\title{
Methane Conversion in Pulsed Corona Discharge Reactors
}

Morris D. Argyle

mdargyle@byu.edu

Gui-Bing Zhao

Sanil John

Ji-Jun Zhang

Linna Wang

See next page for additional authors

Follow this and additional works at: https://scholarsarchive.byu.edu/facpub

Part of the Chemical Engineering Commons

\section{Original Publication Citation}

G.B. Zhao, S. John, J.J. Zhang, L. Wang, S. Muknahallipatna, J.C. Hamann, J.F. Ackerman, M.D. Argyle, O.A. Plumb, "Methane Conversion in Pulsed Corona Discharge Reactors." Chemical Engineering Journal, 125, 67-79, 26. http://www.sciencedirect.com/science/journal/13858947/ $125 / 2$

\section{BYU ScholarsArchive Citation}

Argyle, Morris D.; Zhao, Gui-Bing; John, Sanil; Zhang, Ji-Jun; Wang, Linna; Muknahallipatna, Suresh S.; Hamann, Jerry C.; Ackerman, John F.; and Plumb, Ovid A., "Methane Conversion in Pulsed Corona Discharge Reactors" (2006). Faculty Publications. 300.

https://scholarsarchive.byu.edu/facpub/300 accepted for inclusion in Faculty Publications by an authorized administrator of BYU ScholarsArchive. For more information, please contact ellen_amatangelo@byu.edu. 


\section{Authors}

Morris D. Argyle, Gui-Bing Zhao, Sanil John, Ji-Jun Zhang, Linna Wang, Suresh S. Muknahallipatna, Jerry C. Hamann, John F. Ackerman, and Ovid A. Plumb 


\title{
Methane Conversion in Pulsed Corona Discharge Reactors
}

Gui-Bing Zhao, ${ }^{1}$ Sanil John, ${ }^{1}$ Ji-Jun Zhang, ${ }^{1}$ Linna Wang, ${ }^{1}$ Suresh Muknahallipatna, ${ }^{2}$ Jerry C. Hamann, ${ }^{2}$ John F. Ackerman, ${ }^{1}$ Morris D. Argyle, ${ }^{1}$ Ovid A. Plumb ${ }^{3 *}$

${ }^{1}$ Department of Chemical \& Petroleum Engineering, ${ }^{2}$ Department of Electrical \& Computer Engineering, and ${ }^{3}$ College of Engineering, University of Wyoming, Laramie, WY 82071-3295, USA

\begin{abstract}
This work reports the effect of capacitance, cathode material, gas flow rate and specific energy input on methane conversion, energy efficiency and product selectivity in a co-axial cylinder pulsed corona discharge reactor. Ethane and acetylene appear to be formed from dimerization of $\mathrm{CH}_{3}$ radicals and $\mathrm{CH}$ radicals, respectively, while ethylene is formed mainly from the dehydrogenation of ethane. At a given power input, low capacitance with high pulse frequency results in higher methane conversion and energy efficiency than operation at high capacitance with low pulse frequency. Platinum coated stainless steel cathodes slightly enhance methane conversion relative to stainless steel cathodes, perhaps due to a weak catalytic effect. As specific energy input increases, energy efficiency for methane conversion goes through a minimum, while the selectivity of acetylene has a maximum value. Comparison of methane conversion for different types of plasma reactors shows that the pulsed corona discharge is a potential alternative method for low temperature methane conversion.
\end{abstract}

\section{Submitted to Chemical Engineering Journal, April 7, 2006 \\ CEJ-D-06-00174 \\ REVISED July 12, 2006}

\footnotetext{
* Corresponding author. E-mail: gplumb@uwyo.edu, tel: 307-766-4257, fax: 307-766-4444
} 


\section{Introduction}

The conversion of natural gas (typically $75 \%$ by weight methane) to hydrogen and more valuable higher hydrocarbons, including acetylene, is of great importance to the petrochemical industry. Gaseous plasma is a good source for generating chemically active species, including radicals, electronic excited states, and ions. Direct conversion of methane using various plasma processing technologies, including thermal arc plasma, dielectric-barrier discharge, microwave plasma, and corona discharge, has been studied for many years and has received significant recent attention. Thermal arc plasma is the only plasma technology for converting methane to acetylene that has been demonstrated on an industrial scale. ${ }^{1}$ This process, known as the Huels process, has been practiced for more than 50 years, but the energy consumption is high due to the extremely high temperature (about $2000 \mathrm{~K}){ }^{1}$ Although the selectivity for acetylene formation is high (72.9\%), the gas contains a number of higher unsaturated hydrocarbons and extensive gas purification is required. $^{2}$ Nonthermal plasma technologies are characterized by low gas temperature and high electron temperature because high energy electrons are produced in the gas while the bulk temperature of the gas is unchanged. Nonthermal plasmas overcome the disadvantage of high temperature because the majority of the electrical energy goes into the production of energetic electrons rather than into gas heating. For reactions that are thermodynamically unfavorable and for which low equilibrium conversions are obtained at high reaction temperatures, nonthermal plasmas have an advantage over thermal processes because thermal equilibrium is not achieved. Therefore, nonthermal plasmas are currently being investigated as a promising alternative near-ambient temperature method to convert methane to higher hydrocarbons. ${ }^{3}$ 
Extensive recent research has shown that the hydrocarbon product distribution from a plasma reactor is determined by the type of nonthermal plasma discharge. For example, in a dielectric barrier discharge reactor, ethane is the most abundant reaction product and only small amounts of unsaturated hydrocarbons are formed., ${ }^{4,5}$ In microwave plasma reactors, the product distribution shifts with increasing power input, from ethane to ethylene and finally to acetylene. ${ }^{6-}$ 9 However, the energy efficiency of microwave driven methane conversion is very low, from $0.2 \%$ to $3.3 \%$, as reported by Huang and Suib ${ }^{9}$ and Onoe et al. ${ }^{6}$ High selectivity for acetylene is reported only in pulsed corona discharge reactors (PCDR's). Yang ${ }^{5}$ compared the acetylene selectivity between corona discharge and dielectric barrier discharge reactors. In a corona discharge, the acetylene selectivity reaches $60 \%$, while the acetylene selectivity is less than $6 \%$ in a dielectric barrier discharge. In a co-axial cylinder (CAC) reactor configuration, Zhu et al. ${ }^{10}$ reported about $70 \%$ selectivity to acetylene. Kado et al. ${ }^{11}$ obtained acetylene with approximately 94\% selectivity in a point-to-point (PTP) reactor. They also reported mechanistic pathways of methane conversion in a PTP reactor using isotopic tracer experiments. ${ }^{12}$

The rate of methane conversion in pulsed corona reactors is consistently higher than that reported for microwave or silent discharge. ${ }^{13}$ The combination of high methane reaction rates and high selectivity to acetylene has resulted in a number of recent research efforts on methane conversion in PCDR's. These systematic investigations of methane conversion in PCDR's ${ }^{13-18}$ have included reports of over $85 \%$ acetylene selectivity in a pulsed corona discharge at high pulse frequency in a CAC reactor ${ }^{15}$ and in a PTP reactor. ${ }^{17}$ The effects of pulse voltage rise time, reaction temperature, pulse voltage, pulse frequency, gas flow rate, electrode arrangement, and reactor configuration (CAC reactor and PTP reactor) on methane conversion and product selectivities were analyzed. Pulse frequency has been reported as the most important factor 
influencing acetylene selectivity and methane reaction rate. ${ }^{15}$ A pulse power supply with a frequency up to $10 \mathrm{kHz}$ with a PTP type reactor provided the optimum combination for acetylene and hydrogen production. ${ }^{14}$

Although extensive investigations have been reported for methane conversion in PCDR's, further study is necessary to clarify several issues. First, the effect of the pulse-forming capacitance (the capacitance of the charging capacitor) on methane reaction rate and product selectivities is of interest. For $\mathrm{NO}_{\mathrm{x}}$ conversion in pulsed corona discharges, many investigations ${ }^{19-22}$ have concluded that the pulse-forming capacitance affects energy transfer efficiency from the external circuit to the reactor. However, there are no studies that explore the effect of the pulse-forming capacitance on methane conversion. Second, the effect of the cathode material on methane reaction rate and product selectivities has not received attention. The role of electrode material in plasma-induced reactions is disputed, specifically whether metal electrodes serve simply as conductors of electricity or exhibit a catalytic effect. ${ }^{23}$ Tanaka et al. ${ }^{24}$ and Luo et al. ${ }^{23}$ found that the metal surfaces of the anode have clear catalytic effects for ammonia synthesis and NO decomposition, respectively. However, there are no results that illustrate the effect of cathode material on methane conversion. Third, the effect of gas flow rate or residence time on methane reaction rate is important. Yao et al. ${ }^{15}$ found that gas flow rate did not significantly affect methane conversion rate in a very small CAC reactor $(0.01 \mathrm{~m}$ diameter $\times$ $0.15 \mathrm{~m}$ long). Although Yao et al. ${ }^{17}$ reported that a PTP reactor with high pulse frequency (up to $10 \mathrm{kHz}$ ) can provide high methane reaction rate, scale-up of such PTP reactors is not straightforward. All pulsed corona discharge reactors used for methane conversion have been small, with low flow rates $\left(<2 \times 10^{-4} \mathrm{~mol} \cdot \mathrm{s}^{-1}\right)$ that are far from practical for commercial 
operation. ${ }^{13-18}$ The design and characterization of larger reactors that can accommodate high throughput are critical if these reactors are to be applied successfully in commercial operations.

The goals of this work are to investigate the effect of pulse-forming capacitance, cathode materials, gas flow rates, and specific energy input on methane conversion and product distribution in large-scale co-axial cylinder PCDR's.

\section{Experimental Section}

Figure 1 shows a diagram of the experimental system. The system consists of a reactor with an electrical system built around a thyratron switch, a flow control and distribution system, and a gas sampling system. The reactor is oriented vertically, with the gas flow from bottom to top. Experiments were conducted using three different metal tubes as the cathode: stainless steel, stainless steel coated with a $100 \mathrm{~nm}$ thick layer of platinum, and niobium. The cathode is $0.024 \mathrm{~m}$ in diameter and $0.914 \mathrm{~m}$ in length for the stainless steel and platinum coated stainless steel tubes and $0.60 \mathrm{~m}$ in length for the niobium tube, while the anode is a stainless steel wire 1 $\mathrm{mm}$ in diameter passing axially through the center of the tube. The wire is positively charged, while the tube is grounded. The gas flowing through the reactor tube is converted to plasma by high voltage discharge from the reactor anode.

Figure 2 contains an electrical circuit diagram of the discharge reactor. The electrical circuit of the plasma reactor and the processes of charging and discharging used in this work are quite similar to previous plasma reactor designs used for $\mathrm{NO}_{\mathrm{x}}$ conversion in nonthermal plasma. ${ }^{25}$ The only difference is that a thyratron switch is used to initiate the corona discharge in this work, while a hydrogen switch was used in the previous work. The electrical system can deliver charge voltages from $10 \mathrm{kV}$ to $25 \mathrm{kV}$ at pulse frequencies from 0 to $1000 \mathrm{~Hz}$. The 
capacitor bank provides space for four "doorknob" capacitors, in increments of $640 \mathrm{pF}$. The capacitance of the rest of the electrical system is negligible. The thyratron switch element is cooled with compressed air. The capacitors are charged to the desired voltage using a $40 \mathrm{kV}$ oilcooled high voltage power supply. A thyratron switch is connected directly to the anode of the reactor. On triggering the thyratron, the stored energy in the capacitors is discharged in a few nanoseconds to the anode, giving rise to a high rate of change of voltage (dV/dt) on the anode. This process of charging and discharging the capacitors is repeated based on the thyratron trigger frequency leading to sustained current streamers or plasma. Once triggered, the thyratron will shut off only if the cathode potential becomes higher than the anode potential or the current reaches zero. The anode potential is always higher than the cathode potential and the cathode potential is near zero once the corona is produced. After the corona begins, the current reaches zero only after the capacitor discharges completely. In this way, the energy released by the capacitors per pulse can be calculated from $1 / 2 \mathrm{CV}_{\mathrm{c}}^{2}$, where $\mathrm{C}$ is the pulse forming capacitance as shown in Table 1 and $V_{c}$ is the constant charge voltage before discharge (20 kV for these experiments). The power consumed, $\mathrm{W}\left(\mathrm{J} \cdot \mathrm{s}^{-1}\right)$, was calculated as the product of the input energy per pulse and the pulse frequency, $1 / 2 \mathrm{fCV}_{\mathrm{c}}{ }^{2}$, where $\mathrm{f}$ is pulse frequency in $\mathrm{Hz}$.

In a hydrogen switch based reactor, both reactor pressure and losses in the reactor due to resistance and inductance can cause the switch to open before the capacitor has discharged completely, which would introduce an error in the power calculations based on $1 / 2 \mathrm{CV}_{\mathrm{c}}^{2}$. However, our previous work showed that $97-98 \%$ of energy stored in the capacitors are discharged in to the hydrogen switch based reactor. ${ }^{26}$ By using a thyratron switch, the energy stored in the capacitance can be completely discharged into the plasma. One issue introduced by using a thyratron switch is the thyratron cathode is not grounded, which requires the triggering 
and heating circuit of the thyratron to be electrically isolated using an isolation transformer. This makes the reactor bulky and more expensive. Also, due to the ungrounded cathode, the radio frequency (RF) emission from the thyratron switch is significant and causes malfunctions of the high voltage and current measuring equipment (an oscilloscope). Measurements of instantaneous voltage and current are not reliable due to this RF emission.

The experimental test matrix is shown in Table 1 . The high purity methane (Air Gas Company, 99.97\%) reactant gas flow rates shown in Table 1 are reported at the PCDR entrance conditions of ambient temperature $(\sim 300 \mathrm{~K})$ and $161.4 \mathrm{kPa}$. Stable products were measured with an online Residual Gas Analyzer (RGA, Stanford Research Systems, Inc. QMS100), which is a mass spectrometer with quadrupole probe.

Gas products are sampled through a capillary tube of $2.6 \mathrm{~m}$ length from reactor outlet to the RGA. To perform quantitative measurements, the instrument was calibrated for $\mathrm{H}_{2}, \mathrm{CH}_{4}$, $\mathrm{C}_{2} \mathrm{H}_{2}, \mathrm{C}_{2} \mathrm{H}_{4}, \mathrm{C}_{2} \mathrm{H}_{6}, \mathrm{C}_{3} \mathrm{H}_{6}$ and $\mathrm{C}_{3} \mathrm{H}_{8}$ using gases of certified composition (ultra high purity gases from US Welding and certified binary gas mixtures of He and the respective hydrocarbons from US Airgas). The hydrocarbon samples in the source chamber are ionized to create fragments of different masses. Each specific hydrocarbon has its own characteristic peak. The intensity of each selected ion in the mass spectrum can be described mathematically as follows: ${ }^{27}$

$$
I(M)=\sum_{j} S(M, j) \cdot P(j)
$$

where $I(M)$ is the measured current intensity at mass $M, S(M, j)$ is the sensitivity factor of component $j$ at mass $M$, and $P(j)$ is the partial pressure for component $j$. The number of selected current intensities must be greater than the number of components to obtain quantitative results. The complex sample spectra are deconvoluted using the linear least squares method, which can be expressed as:

$$
\vec{P}=\left(S^{t} \cdot S\right)^{-1} \cdot S^{t} \cdot \vec{I}
$$


where $\vec{P}$ is the vector of estimated partial pressure for every component, $\vec{I}$ is the vector containing the measured current intensities, $S$ is the two dimensional matrix containing the sensitivity factor of each component at specified mass $M$, and $\boldsymbol{S}^{\mathrm{t}}$ is the transpose of $\mathbf{S}$. The sensitivity factor for each component was obtained using both the pure gas and mixtures of certified composition. The fragmentation factor of a specific species at each mass $\mathrm{M}$ (i.e., ratio of ionic signal at mass $\mathrm{M}$ to the ion signal at the principle mass peak) is determined from the pure gas. The sensitivity factor of $\mathrm{N}_{2}$ is obtained from the RGA manufacturer. The sensitivity factors of $\mathrm{H}_{2}$ and $\mathrm{He}$ are determined from binary gas mixtures of $\mathrm{H}_{2}+\mathrm{N}_{2}\left(49.34 \% \mathrm{H}_{2}\right.$ in $\mathrm{N}_{2}$, US Airgas) and $\mathrm{He}+\mathrm{N}_{2}\left(0.972 \%\right.$ He in $\mathrm{N}_{2}, 50.32 \%$ He in $\mathrm{N}_{2}$, and $98.96 \%$ He in $\mathrm{N}_{2}$, US Airgas) because there is no overlap of ionic peaks of $\mathrm{N}_{2}$ and $\mathrm{H}_{2}$ or $\mathrm{N}_{2}$ and He. Then, binary gas mixtures of He and hydrocarbons with different certified concentration are used to determine sensitivity factors for each hydrocarbon because there is no overlap of ionic peaks of $\mathrm{He}$ and the hydrocarbons.

Gas products were sampled when steady-state was reached, which required 20 minutes at low gas flow rate $\left(2.47 \times 10^{-5} \mathrm{~m}^{3} \cdot \mathrm{s}^{-1}\right)$ and 5 minutes at high gas flow rate $\left(9.88 \times 10^{-5} \mathrm{~m}^{3} \cdot \mathrm{s}^{-1}\right)$. For each parameter set, at least two experiments were performed to assure that the results are repeatable. The complex sample spectra of gas products were deconvoluted using the linear least squares method described above to obtain mole fractions of each species. All experimental data were reproducible within a $\pm 10 \%$ error limit, including the RGA and flow measurement uncertainties.

The atomic hydrogen balance at the reactor inlet and outlet was used to estimate the molar flow rate of gas products at the reactor outlet: 


$$
N_{o}=\frac{4 \cdot N_{i, \mathrm{CH}_{4}}}{4 \cdot x_{\mathrm{CH}_{4}}+2 \cdot x_{\mathrm{H}_{2}}+2 \cdot x_{\mathrm{C}_{2} \mathrm{H}_{2}}+4 \cdot x_{C_{2} \mathrm{H}_{4}}+6 \cdot x_{C_{2} \mathrm{H}_{6}}}
$$

where $\mathrm{N}_{\mathrm{i}, \mathrm{CH} 4}$ is the molar flow rate of methane at the reactor inlet $\left(\mathrm{mol} \cdot \mathrm{s}^{-1}\right), \mathrm{N}_{\mathrm{o}}$ is the molar flow rate of the gas phase at the reactor outlet $\left(\mathrm{mol} \cdot \mathrm{s}^{-1}\right)$, and $\mathrm{x}_{\mathrm{i}}$ is the measured mole fraction of species $\mathrm{i}$ at the reactor outlet. The molar flow rate of all major species at the reactor outlet can be obtained from Equation 1. Although hydrocarbon products containing up to three carbons were measured using the RGA, only methane and $\mathrm{C}_{2}$ species were included in Equation 1 because the experimental results showed that the major products were $\mathrm{H}_{2}, \mathrm{C}_{2} \mathrm{H}_{2}, \mathrm{C}_{2} \mathrm{H}_{4}$ and $\mathrm{C}_{2} \mathrm{H}_{6}$, with only traces of higher hydrocarbons, consistent with previously reported results. ${ }^{7,}$ 10, 15-18 Material balance calculations show that Equation 1 is accurate for all power inputs below $~ 225$ W. However, Equation 1 is less accurate for experimental combinations of high power input and low gas flow rate because $\mathrm{C}_{4}+$ hydrocarbons that formed were not detected by the RGA and hydrogen-containing carbonaceous solids were observed in the reactor following these experiments. The amount of carbon deposition was estimated from the carbon balance as follows:

$$
N_{o, \mathrm{C}}=N_{i, \mathrm{CH}_{4}}-N_{o} \cdot\left[x_{\mathrm{CH}_{4}}+2 \cdot\left(x_{\mathrm{C}_{2} \mathrm{H}_{2}}+x_{C_{2} \mathrm{H}_{4}}+x_{C_{2} \mathrm{H}_{6}}\right)\right]
$$

where $\mathrm{N}_{\mathrm{o}, \mathrm{C}}$ is the molar rate of carbon deposition in the reactor $\left(\mathrm{mol} \cdot \mathrm{s}^{-1}\right.$ ). The solid carbonaceous deposits were analyzed by magic angle spinning (MAS) nuclear magnetic resonance (NMR) spectroscopy (Bruker Avance DRX-700).

Several parameters used to describe the experimental results are defined as follows:

(1) Specific energy input, $\mathrm{E}_{\mathrm{s}}\left(\mathrm{kJ} \cdot \mathrm{mol}^{-1}\right)$ :

$$
E_{s}=\frac{W}{1000 \cdot u \cdot 64.7}
$$


where $\mathrm{u}$ is gas flowrate $\left(\mathrm{m}^{3} \cdot \mathrm{s}^{-1}\right)$ of UHP methane and 64.7 is the constant number of moles per unit reactor volume $\left(\mathrm{mol} \mathrm{m}^{-3}\right)$ at $161.4 \mathrm{kPa}$ and $300 \mathrm{~K}$.

(2) Methane conversion (\%):

$$
X=\left[1-\frac{N_{o, \mathrm{CH}_{4}}}{N_{i, \mathrm{CH}_{4}}}\right] \cdot 100
$$

where $\mathrm{N}_{\mathrm{o}, \mathrm{CH}}$ is the molar flow rate of methane at the reactor outlet.

(3) Selectivity for hydrocarbons, hydrogen, and carbon, (\%):

$$
\begin{aligned}
& S_{C n H m}=\frac{n \cdot N_{o, \text { CnHm }}}{C H_{4 \text { conv }}} \cdot 100 \\
& S_{H_{2}}=\frac{0.5 \cdot N_{o, H_{2}}}{C H_{4 \text { conv }}} \cdot 100 \\
& S_{C}=\frac{N_{o, C}}{C H_{4 \text { conv }}} \cdot 100
\end{aligned}
$$

where $\mathrm{N}_{\mathrm{o}, \mathrm{CnHm}}$ and $\mathrm{N}_{\mathrm{o}, \mathrm{H}_{2}}$ are molar flow rates of hydrocarbon and hydrogen at the reactor outlet, respectively, $\mathrm{N}_{\mathrm{o}, \mathrm{C}}$ is the molar rate of carbon deposition within the reactor, and $\mathrm{CH}_{4 \text { conv }}$ is the reaction rate of methane $\left(\mathrm{mol} \cdot \mathrm{s}^{-1}\right)$. These definitions of selectivity are consistent with those used by other investigators. ${ }^{8,10}$ Carbon selectivity includes all products with more than four carbons. As reported in the Results and Discussion section, the carbon selectivity was negligible for most experiments and only became measurable at power inputs greater than $225 \mathrm{~W}$.

As discussed above, the major products of methane conversion are $\mathrm{C}_{2} \mathrm{H}_{2}, \mathrm{C}_{2} \mathrm{H}_{4}, \mathrm{C}_{2} \mathrm{H}_{6}, \mathrm{C}$, and $\mathrm{H}_{2}$. The resulting reactions are all endothermic:

$$
\begin{array}{rlrl}
\mathrm{CH}_{4} & \rightarrow \mathrm{C}+2 \mathrm{H}_{2} & \Delta H_{1}^{o}=74.9 \mathrm{~kJ} / \mathrm{mol} \mathrm{CH}_{4} \\
\mathrm{CH}_{4} & \rightarrow \frac{1}{2} \mathrm{C}_{2} \mathrm{H}_{2}+\frac{3}{2} \mathrm{H}_{2} & \Delta H_{2}^{o}=188.2 \mathrm{~kJ} / \mathrm{mol} \mathrm{CH}_{4} \\
\mathrm{CH}_{4} \rightarrow \frac{1}{2} \mathrm{C}_{2} \mathrm{H}_{4}+\mathrm{H}_{2} & \Delta H_{3}^{o}=100.9 \mathrm{~kJ} / \mathrm{mol} \mathrm{CH}_{4}
\end{array}
$$




$$
\mathrm{CH}_{4} \rightarrow \frac{1}{2} \mathrm{C}_{2} \mathrm{H}_{6}+\frac{1}{2} \mathrm{H}_{2} \quad \Delta \mathrm{H}_{4}^{o}=32.5 \mathrm{~kJ} / \mathrm{mol} \mathrm{CH}_{4}
$$

Energy efficiency is defined as the ratio of the minimum energy required to convert methane to $\mathrm{C}, \mathrm{C}_{2} \mathrm{H}_{2}, \mathrm{C}_{2} \mathrm{H}_{4}$ and $\mathrm{C}_{2} \mathrm{H}_{6}$ to the actual energy input in the reactor.

(4) Energy efficiency (\%):

$$
E=\frac{1000 \cdot\left(N_{o, C} \cdot \Delta H_{1}^{0}+2 \cdot N_{o, C_{2} H_{2}} \cdot \Delta H_{2}^{0}+2 \cdot N_{o, C_{2} H_{4}} \cdot \Delta H_{3}^{0}+2 \cdot N_{o, C_{2} H_{6}} \cdot \Delta H_{4}^{0}\right)}{W} \times 100
$$

\section{Results and Discussion}

Product distribution. Figures 3(a), (b) and (c) show the reactor product distribution as a function of power input at a flowrate of $2.47 \times 10^{-5} \mathrm{~m}^{3} \cdot \mathrm{s}^{-1}$ and pulse-forming capacitance of 1920 $\mathrm{pF}$ for the stainless steel tube (SS), platinum coated stainless steel tube (Pt/SS), and the niobium (Nb) tube, respectively. As mentioned previously, the major products were $\mathrm{H}_{2}, \mathrm{C}_{2} \mathrm{H}_{2}, \mathrm{C}_{2} \mathrm{H}_{4}$ and $\mathrm{C}_{2} \mathrm{H}_{6}$, with only traces of higher hydrocarbons, except at power inputs $>\sim 225 \mathrm{~W}$. The methane concentration decreases with increasing power input, indicating that methane conversion increases with increasing power input. Meanwhile, concentrations of $\mathrm{H}_{2}$ and $\mathrm{C}_{2} \mathrm{H}_{2}$ increase with increasing power input. The $\mathrm{C}_{2} \mathrm{H}_{6}$ concentration initially increases with increasing power input, but reaches a maximum at about $300 \mathrm{~W}$ power input and then decreases. At low power input (less than $200 \mathrm{~W}$ ), $\mathrm{C}_{2} \mathrm{H}_{4}$ is not detectable. The $\mathrm{C}_{2} \mathrm{H}_{4}$ concentration begins to increase from zero near the point where the $\mathrm{C}_{2} \mathrm{H}_{6}$ concentration reaches a maximum. With further increases in power input, the $\mathrm{C}_{2} \mathrm{H}_{4}$ concentration reaches a maximum and then decreases [Figures 3(a) and (b)]. The trends of the $\mathrm{C}_{2} \mathrm{H}_{4}$ and $\mathrm{C}_{2} \mathrm{H}_{6}$ concentrations with power input suggest that $\mathrm{C}_{2} \mathrm{H}_{4}$ formation is primarily a result of dehydrogenation of $\mathrm{C}_{2} \mathrm{H}_{6}$. The concentrations of $\mathrm{C}_{2} \mathrm{H}_{4}$ and $\mathrm{C}_{2} \mathrm{H}_{6}$ are always less than $2 \mathrm{~mol} \%$, while the concentration of $\mathrm{C}_{2} \mathrm{H}_{2}$ reaches nearly $10 \mathrm{~mol} \%$. The concentration of $\mathrm{C}_{2} \mathrm{H}_{2}$ is always greater than 2 mol\% even when $\mathrm{C}_{2} \mathrm{H}_{4}$ is not detectable (at 
power inputs less than $200 \mathrm{~W}$ ), which suggests that $\mathrm{C}_{2} \mathrm{H}_{2}$ formation occurs via dimerization of $\mathrm{CH}$ radicals in the streamer channels instead of by dehydrogenation of $\mathrm{C}_{2} \mathrm{H}_{4}$.

In corona discharges, a high-voltage, short-duration $(<100 \mathrm{~ns})^{22,} 28$ electrical discharge between non-uniform electrodes is used to produce streamers through the growth of electron avalanches formed by electron collision ionization events in the gas. A streamer is a region of highly ionized gas where a wide range of active radicals and chemical species are formed through electron collision reactions with the background gas. These active species, in turn, initiate bulk phase reactions that lead to methane conversion. Therefore, all active species are first formed in the streamer.

Many investigators ${ }^{4}, 7,12,15,29,30$ have explored the mechanism of $\mathrm{CH}, \mathrm{CH}_{2}$ and $\mathrm{CH}_{3}$ radical formation. The generally accepted mechanism is via direct electron collision reactions with methane (E1a-c),

$$
\begin{aligned}
& \mathrm{e}+\mathrm{CH}_{4} \rightarrow \mathrm{CH}_{3}+\mathrm{H}+\mathrm{e} \\
& \mathrm{e}+\mathrm{CH}_{4} \rightarrow \mathrm{CH}_{2}+\mathrm{H}+\mathrm{H}+\mathrm{e} \\
& \mathrm{e}+\mathrm{CH}_{4} \rightarrow \mathrm{CH}+\mathrm{H}+\mathrm{H}+\mathrm{H}+\mathrm{e}
\end{aligned}
$$

which initiate the subsequent diemerization reactions responsible for formation of higher hydrocarbons. However, the relative importance of electron collision reactions E1a-c and the yields of $\mathrm{CH}, \mathrm{CH}_{2}$ and $\mathrm{CH}_{3}$ radicals depend on energy input per pulse and specific reactor configuration. Kado et al. ${ }^{12}$ explored experimentally the mechanism of $\mathrm{CH}_{4}$ decomposition in a point-to-point reactor using isotopically labeled reactants and products. They showed that the dominant reaction pathways include direct dissociation of methane into $\mathrm{CH}$ and atomic $\mathrm{C}$ radicals, which then dimerize to form $\mathrm{C}_{2} \mathrm{H}_{2}$ and $\mathrm{C}_{2}$ radicals. The $\mathrm{C}_{2}$ radicals are subsequently hydrogenated to form acetylene, which produces $\mathrm{C}_{2} \mathrm{D}_{2}$ and $\mathrm{C}_{2} \mathrm{HD}$ in the presence of $\mathrm{D}_{2}$ added to 
the reaction mixture. Yao et al. ${ }^{15}$ performed an experimental investigation on methane conversion in plasma reactors with CAC reactor configuration, with cylinder diameter of $10 \mathrm{~mm}$, cylinder length of $150 \mathrm{~mm}$, and anode wire diameters of $0.5 \mathrm{~mm}$ and $2.9 \mathrm{~mm}$. At an energy input of $7.5 \mathrm{~mJ} /$ pulse, they proposed that the major products of electron collision with methane are $\mathrm{CH}$ and $\mathrm{CH}_{2}$ radicals based on the observed product selectivities. Kirikov et al. ${ }^{29}$ investigated theoretically the free radical formation mechanism formation mechanism in a pulsed surface discharge plasma reactor with two parallel electrodes situated on a dielectric plate and found that the primary products are $\mathrm{CH}$ and $\mathrm{CH}_{3}$ radicals when the energy input per pulse is larger than $20 \mathrm{~mJ}$. When the energy input is larger than $30 \mathrm{~mJ} /$ pulse, the concentration of the $\mathrm{CH}$ radicals exceeds the concentration of $\mathrm{CH}_{3}$ radicals, which is about three orders of magnitude higher than the $\mathrm{CH}_{2}$ radical concentration.

Although the reactor geometry used in this work is very different from that analyzed by Kirikov et al. ${ }^{29}$, our results appear to be consistent with their theoretical results. ${ }^{29}$ For an energy input of $384 \mathrm{~mJ} /$ pulse with our larger reactor and reactant flow rates, the results of Figure 3 suggest that the majority of the radicals formed in the discharge channel are $\mathrm{CH}$ radicals, with a smaller number of $\mathrm{CH}_{3}$ radicals, and very small numbers of $\mathrm{CH}_{2}$ radicals because the concentration of $\mathrm{C}_{2} \mathrm{H}_{2}$ is far larger than that of $\mathrm{C}_{2} \mathrm{H}_{6}$ and $\mathrm{C}_{2} \mathrm{H}_{4}$, and the concentration of $\mathrm{C}_{2} \mathrm{H}_{4}$ is close to zero at power inputs less than $200 \mathrm{~W}$. The results are consistent with $\mathrm{CH}$ radicals as the main active species leading to the synthesis of $\mathrm{C}_{2} \mathrm{H}_{2}$ through the following rapid reactions: ${ }^{7,31}$

$$
\begin{array}{ll}
\mathrm{CH}+\mathrm{CH} \rightarrow \mathrm{C}_{2} \mathrm{H}_{2} & \mathrm{k}=1.20 \times 10^{14} \mathrm{~cm}^{3} \cdot \mathrm{mol}^{-1} \cdot \mathrm{s}^{-1} \\
\mathrm{CH}+\mathrm{CH}_{3} \rightarrow \mathrm{C}_{2} \mathrm{H}_{3}+\mathrm{H} & \mathrm{k}=3.01 \times 10^{13} \mathrm{~cm}^{3} \cdot \mathrm{mol}^{-1} \cdot \mathrm{s}^{-1} \\
\mathrm{C}_{2} \mathrm{H}_{3}+\mathrm{H} \rightarrow \mathrm{C}_{2} \mathrm{H}_{2}+\mathrm{H}_{2} & \mathrm{k}=1.20 \times 10^{13} \mathrm{~cm}^{3} \cdot \mathrm{mol}^{-1} \cdot \mathrm{s}^{-1}
\end{array}
$$


This would explain the increase in $\mathrm{C}_{2} \mathrm{H}_{2}$ concentration with increasing power input. $\mathrm{CH}_{3}$ radicals appear to be the main active species leading to the formation of $\mathrm{C}_{2} \mathrm{H}_{6}$ through the following reaction: ${ }^{7}, 31$

$$
\mathrm{CH}_{3}+\mathrm{CH}_{3} \rightarrow \mathrm{C}_{2} \mathrm{H}_{6} \quad \mathrm{k}=3.61 \times 10^{13} \mathrm{~cm}^{3} \cdot \mathrm{mol}^{-1} \cdot \mathrm{s}^{-1}
$$

Dehydrogenation of $\mathrm{C}_{2} \mathrm{H}_{6}$ to $\mathrm{C}_{2} \mathrm{H}_{4}$ is highly temperature dependent: ${ }^{7,31}$

$$
\mathrm{H}+\mathrm{C}_{2} \mathrm{H}_{6} \rightarrow \mathrm{C}_{2} \mathrm{H}_{5}+\mathrm{H}_{2} \quad \mathrm{k}=1.44 \times 10^{9} \mathrm{~T}^{1.5} \exp (-3730 / \mathrm{T}) \mathrm{cm}^{3} \cdot \mathrm{mol}^{-1} \cdot \mathrm{s}^{-1}
$$

where $\mathrm{T}$ is in $\mathrm{K}$ and

$$
\mathrm{H}+\mathrm{C}_{2} \mathrm{H}_{5} \rightarrow \mathrm{C}_{2} \mathrm{H}_{4}+\mathrm{H}_{2} \quad \mathrm{k}=3.01 \times 10^{13} \mathrm{~cm}^{3} \cdot \mathrm{mol}^{-1} \cdot \mathrm{s}^{-1}
$$

At ambient temperatures, the reaction rate for R9 is negligible and only contributes to $\mathrm{C}_{2} \mathrm{H}_{4}$ formation at higher temperatures. In this work, the temperature is close to ambient at low power inputs, leading to negligible $\mathrm{C}_{2} \mathrm{H}_{4}$ formation via dehydrogenation of $\mathrm{C}_{2} \mathrm{H}_{6}$. However, the reactor temperature increases with increasing power input, especially near the outlet, leading to dehydrogenation of $\mathrm{C}_{2} \mathrm{H}_{6}$.

To verify the importance of thermal reactions to $\mathrm{C}_{2} \mathrm{H}_{4}$ formation from $\mathrm{C}_{2} \mathrm{H}_{6}$, the temperature profile within the reactor must be known. However, the temperature cannot be measured accurately because the thyratron RF emission heavily disturbs thermocouple signals. Mechanical, bimetallic thermometers placed in the reactor outlet stream proved to be relatively unresponsive and displayed near ambient temperatures, despite the fact that the reactor external support casing (a $0.05 \mathrm{~m}$ diameter stainless steel tube concentric to the reactor cathode) was hot to the touch (>350 K) near the reactor outlet. Therefore, the hydrogen switch based reactor (used for $\mathrm{NO}_{\mathrm{x}}$ conversion in our previous work ${ }^{22,25,28,32-37}$ ) with the same reactor geometry as the thyratron-based reactor (tube length: $0.914 \mathrm{~m}$; tube diameter: $0.024 \mathrm{~m}$, wire diameter: $1 \mathrm{~mm}$ ) was used during methane conversion to estimate the temperatures in the thyratron-based reactor. 
Figure 4 shows the measured reactor tube wall temperature function of specific energy input. The data were obtained $0.16 \mathrm{~m}$ from the reactor outlet after 10 minutes of operation at a reactor inlet flow rate of $9.76 \times 10^{-5} \mathrm{~m}^{3} \cdot \mathrm{s}^{-1}$ and pressure of $175 \mathrm{kPa}$ of pure methane. The tube wall temperature linearly increases with increasing specific energy input. Based on extrapolation of Figure 4 and heat transfer calculations, the estimated temperature at the center of the reactor at a power input of $200 \mathrm{~W}$ (corresponding to a specific energy input of $125 \mathrm{~kJ}^{\mathrm{mol}} \mathrm{mol}^{-1}$ ) is $853 \mathrm{~K}$, which is sufficient to initiate a significant rate of $\mathrm{C}_{2} \mathrm{H}_{6}$ dehydrogenation based on the rate constant for R9 and the measured outlet $\mathrm{C}_{2} \mathrm{H}_{6}$ concentration. The experimental results for $\mathrm{C}_{2} \mathrm{H}_{4}$ and $\mathrm{C}_{2} \mathrm{H}_{6}$ concentrations shown in Figure 3 are consistent with these arguments.

Figure 5 shows the H/C ratio of the outlet gas as a function of power input at the same conditions as Figure 3. If the $\mathrm{H} / \mathrm{C}$ ratio of the outlet gas is equal to 4, the material balance indicates that the formation of $\mathrm{C}_{3}+$ hydrocarbons and the deposition of carbonaceous material within the reactor are negligible. The results of Figure 5 show that $\mathrm{C}_{3}+$ hydrocarbons or carbonaceous deposits are formed only at power inputs higher than $\sim 225 \mathrm{~W}$, which is consistent with our experimental observation. Carbonaceous solid deposition was observed only at pulse frequencies higher than $800 \mathrm{~Hz}$, corresponding to $307 \mathrm{~W}$ power input at $1920 \mathrm{pF}$ capacitance. Lighter liquid hydrocarbons, such as benzene, were probably formed in the power interval between 225 and 307 W (in which no solid deposits were observed in the reactor and yet the H/C ratio was calculated as $>4$ ), but these species were not detectable with the RGA. Therefore, although no solid deposits were observed in the reactor, the mass balance calculation accounted for these species as missing carbon. This assumption is consistent with analysis of the carbonaceous residues by NMR that showed they consisted of polynuclear aromatic compounds, which were probably formed from lighter molecular weight aromatic intermediates. 
The effect of capacitance. Figure 6 shows the effect of capacitance on methane conversion, energy efficiency and product selectivity for the Pt/SS tube at a flowrate of $2.47 \times$ $10^{-5} \mathrm{~m}^{3} \cdot \mathrm{s}^{-1}$. Two capacitances are compared in this figure: filled symbols correspond to 1920 $\mathrm{pF}$, while open symbols correspond to $1280 \mathrm{pF}$. At a given power input $>150 \mathrm{~W}$, methane conversion and energy efficiency are higher for the $1280 \mathrm{pF}$ results compared to those obtained at $1920 \mathrm{pF}$, as shown in Figure 6(a). The selectivity for $\mathrm{C}_{2} \mathrm{H}_{6}$ at $1280 \mathrm{pF}$ is lower than that at $1920 \mathrm{pF}$, while $\mathrm{C}_{2} \mathrm{H}_{4}$ selectivities are approximately the same for both levels of capacitance (Figure 6(b)). The $\mathrm{C}_{2} \mathrm{H}_{2}$ selectivity at $1280 \mathrm{pF}$ is slightly higher than that for $1920 \mathrm{pF}$, while carbon selectivity does not appear to change with capacitance (Figure 6(c)).

Identical power inputs can be achieved using high capacitance and low pulse frequency or low capacitance with high pulse frequency, as discussed previously. The results of Figure 6 indicate that operation of the PCDR at low capacitance with high pulse frequency is better than operation at high capacitance with low pulse frequency because methane conversion, energy efficiency, and acetylene selectivity (which is a more valuable product than ethane) are slightly higher at low capacitance with high pulse frequency. These results are consistent with the results of Yao et al., ${ }^{15}$ who found that high pulse frequency promotes acetylene formation and improves methane conversion.

In addition, Uhm and Lee ${ }^{19}$ reported that reactor capacitance plays a pivotal role in the energy efficiency of nonthermal plasma reactors. Mok et al. ${ }^{20}$ found that when the pulseforming capacitance is five times larger than the geometric capacitance of the reactor, the energy efficiency was maximized. Chung et al. ${ }^{21}$ found the maximum energy efficiency for NO conversion in a PCDR when the pulse-forming capacitance is 3.4 times larger than the reactor 
capacitance. The NO reactor results should be relevant because both $\mathrm{CH}_{4}$ and $\mathrm{NO}$ reactions originate with similar electron collision reactions. ${ }^{7,} 31$ These findings indicate that the energy efficiency of a PCDR can be improved by keeping the ratio of pulse-forming capacitance to reactor capacitance low, typically $3-5$. The capacitance of a co-axial cylinder is defined as: ${ }^{38}$

$$
C_{R}=\frac{2 \pi \varepsilon L}{\ln (R / r)}
$$

where $\varepsilon$ is the permittivity of $\mathrm{CH}_{4}, L$ is the length of the reactor, $R$ is the inner radius of the cathode (reactor tube) and $r$ is the outer radius of the anode (central wire). As our reactor has a capacitance of $18.3 \mathrm{pF}$, the ratio of the pulse-forming capacitance $\left(\mathrm{C}_{\mathrm{P}}\right)$ to reactor capacitance $\left(\mathrm{C}_{\mathrm{R}}\right)$ for our reactor configuration is:

$$
\frac{C_{P}}{C_{R}}=\frac{C_{P}}{18.3}
$$

Therefore, by decreasing pulse-forming capacitance from $1920 \mathrm{pF}$ to $1280 \mathrm{pF}$, the ratio of the pulse-forming capacitance to the reactor capacitance decreases from 105 to 70 . Although both values are far larger than the optimal ratio suggested by Mok et al. ${ }^{20}$ and Chung et al., ${ }^{21}$ our results indicate a trend toward improved conversion and energy efficiency as the ratio is decreased toward the optimum.

The effect of cathode material. Figure 7 illustrates the effect of cathode material on methane conversion, energy efficiency, and selectivity of $\mathrm{C}_{2} \mathrm{H}_{4}, \mathrm{C}_{2} \mathrm{H}_{6}, \mathrm{C}_{2} \mathrm{H}_{2}$ and carbon for the SS and Pt/SS tubes at the same experimental conditions. For power inputs less than $225 \mathrm{~W}$, methane conversion for both SS and Pt/SS cathodes is nearly the same. However, at higher power inputs, methane conversion and energy efficiency for the Pt/SS cathode are slightly higher than for the SS cathode [Figure 7(a)], suggesting that the Pt coating may have a small catalytic 
effect on methane conversion. Platinum is a known catalyst for methane conversion. ${ }^{39,40}$ However, Pt catalytic reactions typically require high reaction temperature (723 to $773 \mathrm{~K}$ ). ${ }^{41}$ The temperature of the cathode and the outlet gas in our experiments increased with increasing power input (and could easily exceed $750 \mathrm{~K}$ ), which would enhance any catalytic effect of the Pt coated cathode and would be consistent with the experimental results in Figure 7(a). A Pt coated anode may be more effective as a catalyst than the cathode, as suggested by the results of Eichwald et al., ${ }^{42}$ who used a mathematical model to simulate the dynamics of streamer discharges in flue gas. They found the temperature close to the wire (anode) is much higher (>800 K) than the temperatures near the tube wall (cathode) because of the strong electric field in the vicinity of the wire. Therefore, a platinum coated anode should provide a larger catalytic effect than a Pt coated cathode, as evidenced by the strong catalytic effect reported by Luo et $a .^{23}$ for a Pt coated stainless steel rod anode used for NO conversion.

Figure 7(b) shows that $\mathrm{C}_{2} \mathrm{H}_{6}$ selectivity is slightly lower and $\mathrm{C}_{2} \mathrm{H}_{4}$ selectivity is slightly higher for the platinum coated cathode compared to the plain stainless steel tube. Low $\mathrm{C}_{2} \mathrm{H}_{6}$ selectivity and high $\mathrm{C}_{2} \mathrm{H}_{4}$ selectivity for the Pt coated cathode is consistent with the known ability of platinum to dehydrogenate alkanes, ${ }^{41}$ in this case of $\mathrm{C}_{2} \mathrm{H}_{6}$ to $\mathrm{C}_{2} \mathrm{H}_{4}$.

Comparison of $\mathrm{C}_{2} \mathrm{H}_{2}$ and carbon selectivities shows no distinct trends between the stainless steel and platinum coated stainless steel cathodes.

The effect of gas flowrate. Figures 8(a) and (b) show the effect of gas flow rate on methane conversion, energy efficiency and product selectivity for the stainless steel tube at power inputs of $154 \mathrm{~W}$ and $307 \mathrm{~W}$, respectively. Figure 8(a) illustrates that at low power input, methane conversion decreases and energy efficiency increases with increasing gas flow rate. 
Selectivity to acetylene and hydrogen decreases with increasing gas flow rate, while selectivity to ethane increases with increasing gas flow rate. No carbon and ethylene were detected at this lower power input, consistent with the results in Figures 3 and 5. With increasing gas flow rate, specific energy input decreases at the same overall power input. Therefore, methane conversion decreases with increasing gas flow rate. At high gas flow rate and lower methane conversion, decreasing rates of radical recombination reactions, such as methane formation by recombination reaction of $\mathrm{H}$ and $\mathrm{CH}_{3}$ radicals, results in higher energy efficiency at higher gas flow rates. However, high gas flow rates also decrease the concentration of $\mathrm{H}$ radicals in the streamers, indicating that the dehydrogenation rate of $\mathrm{CH}_{3}$ to $\mathrm{CH}$ is reduced, which leads to decreasing selectivity for acetylene and increasing $\mathrm{C}_{2} \mathrm{H}_{6}$ selectivity with increasing gas flow rate. Selectivity for hydrogen decreases with increasing gas flow rate (following the trend for $\mathrm{C}_{2} \mathrm{H}_{2}$ ) because methane conversion to acetylene (R2) produces three times as much hydrogen as methane conversion to ethane (reaction R4).

At higher power inputs, as shown in Figure 8(b), similar trends are observed when the gas flow rate is greater than $4 \times 10^{-5} \mathrm{~m}^{3} \cdot \mathrm{s}^{-1}$. However, at low gas flow rates, the same trends do not hold because a minimum in energy efficiency and a maximum in $\mathrm{C}_{2} \mathrm{H}_{2}$ selectivity occur and carbon deposition is observed at the lowest gas flow rate. These observations are explained in the following section.

The effect of specific energy input. Specific energy combines the effects of power input and gas flow rate, as shown in Equation 3. Figure 9 presents the effect of specific energy input on methane conversion and product selectivity for the entire range of power input and flow rate for the stainless steel cathode. 
In the PCDR, activation and conversion of methane occur by collision of methane molecules with energetic electrons: ${ }^{29}$

$$
\mathrm{CH}_{4}+\mathrm{e} \rightarrow \mathrm{CH}_{\mathrm{n}}+(4-\mathrm{n}) \mathrm{H} \rightarrow \text { products }
$$

During the formation of products shown in R11, methane dehydrogenation is the rate determining step because electron collision reaction of methane determines the subsequent product selectivity and methane reaction rate. ${ }^{29}$ Therefore, the net reaction rate for methane conversion can be written as

$$
-\mathrm{d}\left[\mathrm{CH}_{4}\right] / \mathrm{dt}=\mathrm{k}_{0} \mathrm{n}_{\mathrm{e}}\left[\mathrm{CH}_{4}\right]
$$

where $\left[\mathrm{CH}_{4}\right]$ is the mole concentration of methane $\left(\mathrm{mol} \cdot \mathrm{m}^{-3}\right), \mathrm{n}_{\mathrm{e}}$ is the electron concentration $\left(\mathrm{mol} \cdot \mathrm{m}^{-3}\right)$, and $\mathrm{k}_{0}$ is the rate constant $\left(\mathrm{m}^{3} \cdot \mathrm{mol}^{-1} \cdot \mathrm{s}^{-1}\right)$. Assuming that the electron concentration is proportional to power input, ${ }^{25}$ Equation 11 can be solved in terms of methane conversion (X) as

$$
\ln (1-\mathrm{X})=-\mathrm{k}_{0} \cdot \alpha \cdot \mathrm{W} \cdot \mathrm{V} / \mathrm{u}
$$

where $\alpha$ is the proportionality constant for electron concentration with power input and $\mathrm{V}$ is the reactor volume. Substituting Equation 3 into Equation 11 produces the following result:

$$
\ln (1-\mathrm{X})=-\mathrm{k} \cdot \mathrm{E}_{\mathrm{s}}
$$

where $\mathrm{k}$ is a proportionality constant with units of $\mathrm{mol} \cdot \mathrm{kJ}^{-1}$.

Figure 9(a) shows that $\ln (1-X)$ vs. $E_{s}$ has a linear relationship for specific energies less than about $130 \mathrm{~kJ} \cdot \mathrm{mol}^{-1}$ (point A). The slope of $\ln (1-\mathrm{X})$ vs. $\mathrm{E}_{\mathrm{s}}$ in this region is $7.17 \times 10^{-4}$ mol $\cdot \mathrm{kJ}^{-1}$, which provides a value for the proportionality constant, $\mathrm{k}$.

Figure 9(b) shows the effect of specific energy input on energy efficiency. Energy efficiency initially decreases with increasing specific energy input until reaching a minimum at $\sim 130 \mathrm{~kJ} \cdot \mathrm{mol}^{-1}$ (point A) and then increases. Reactor temperature increases with increasing specific energy input, the most pronounced effect being at the outlet. Yao et al. ${ }^{15}$ found that the 
impedance of methane decreases with increasing gas temperature. Low impedance of methane at high temperature leads to more inefficient energy delivery from the external circuit to the reactor. Therefore, energy efficiency initially decreases with increasing specific energy input. However, after the reactor temperature reaches a critical value, thermal reactions, especially dehydrogenation reactions, may begin to be significant because their rates increase exponentially with temperature (e.g., reaction R9). ${ }^{7}$ These thermal reactions can further enhance methane conversion. As discussed earlier in association with Figure 4, the estimated temperature in the reactor at a specific energy input of $125 \mathrm{~kJ} \mathrm{~mol}^{-1}$ is $853 \mathrm{~K}$. Therefore, thermal reactions are likely the reason for the observed increase in energy efficiency with increasing specific energy input at high specific energy. If the reactor were adiabatic and all energy input were dissipated in heating the gas, the calculated methane temperature is about $2000 \mathrm{~K}$ at a specific energy input of $130 \mathrm{~kJ} \cdot \mathrm{mol}^{-1}$. The actual temperatures in our non-adiabatic reactor are well below $2000 \mathrm{~K}$, but at an estimated $\sim 853 \mathrm{~K}$, they appear to be high enough to initiate thermal reactions. The onset of thermal reactions would explain the lack of linearity between $\ln (1-X)$ and $E_{s}$ [Figure 9(a)] at specific energy inputs $>\sim 130 \mathrm{~kJ} \cdot \mathrm{mol}^{-1}$ and the resulting minimum value for energy efficiency in methane conversion observed at low gas flowrates (corresponding to high specific energy input) [Figure 8(b)].

Figure 9(c) shows the effect of specific energy input on selectivity of acetylene, ethylene, ethane and carbon. Acetylene selectivity initially increases with increasing specific energy input, but after reaching a maximum at $130 \mathrm{~kJ} \cdot \mathrm{mol}^{-1}$ (point A), it decreases with further increases in specific energy. The selectivities for ethylene and carbon are initially zero. Near the point where acetylene selectivity reaches a maximum and begins to decrease, the ethylene and carbon selectivities increase with increasing specific energy input. These results are consistent with 
those shown in Figures 8(a) and (b), which have been discussed previously. The data imply an increase in ethylene selectivity due to ethane dehydrogenation. At specific energies $>\sim 130$ $\mathrm{kJ} \cdot \mathrm{mol}^{-1}$, dehydrogenation of acetylene apparently results in deposition of carbonaceous residues, consistent with the results of other studies conducted at higher reaction temperatures. ${ }^{2,} 43$ Formation of solid carbonaceous deposits from acetylene would also explain the decrease in acetylene selectivity with increasing specific energy. Similar reasoning explains the trend in acetylene selectivity in Figure 8(d).

Figure 9(d) shows the effect of specific energy input on the hydrogen selectivity. At specific energy inputs less than $50 \mathrm{~kJ} \cdot \mathrm{mol}^{-1}$, the hydrogen selectivity increases rapidly with increasing specific energy input, corresponding to the similar increase in acetylene selectivity and the decrease in ethane selectivity shown in Figure 9(c). At specific energy inputs greater than $50 \mathrm{~kJ} \cdot \mathrm{mol}^{-1}$, the selectivity of hydrogen slowly increases with increasing specific energy input.

Figures $10(\mathrm{a})$ and (b) show a plot of $\ln (1-\mathrm{X})$ vs. $\mathrm{E}_{\mathrm{s}}$ for the $\mathrm{Pt} / \mathrm{SS}$ and $\mathrm{Nb}$ tubes, respectively. The slope of $\ln (1-\mathrm{X})$ vs. $\mathrm{E}_{\mathrm{s}}$ for the $\mathrm{Pt} / \mathrm{SS}$ and $\mathrm{Nb}$ tubes are slightly higher than that for the SS tube, supporting the earlier conjecture that the cathode material has only a weak catalytic effect on methane conversion, as illustrated in Figure 7.

Table 2 compares energy efficiency and operating conditions for plasma methane conversion in different types of plasma reactors. Microwave discharge and dielectric barrier discharge plasmas have low energy efficiencies (< 3\%). For corona discharge reactors, energy efficiency in a PTP reactor with high pulse frequency is highest $(\sim 50 \%),{ }^{17}$ even higher than the commercialized Huels process. However, the PTP reactor is very small and operates with low gas throughput. The reactor in this work processes gas flow rates that are one order of 
magnitude larger than the PTP reactor studied by Yao et al. ${ }^{15,17}$ and over 100 times larger than the PTP reactor used by Kado et al. ${ }^{12}$ The highest energy efficiency achieved in this study, 33\%, is higher than the CAC corona discharge reactor reported by Yao et $\mathrm{al}^{15}$ and close to that reported for the Huels process. However, methane conversion at this highest energy efficiency is only 2\%, as compared to $70.5 \%$ in Huels process. ${ }^{1}$

\section{Conclusions}

This work shows that capacitance, cathode material, gas flowrate and specific energy each have an effect on methane conversion, energy efficiency and product selectivity in co-axial cylinder pulsed corona discharge reactors. The formation of ethane and acetylene is apparently the result of dimerization of $\mathrm{CH}_{3}$ and $\mathrm{CH}$ radicals, respectively, while the formation of ethylene results from the dehydrogenation of ethane. At the same power input, low capacitance with high pulse frequency results in for higher methane conversion and energy efficiency than operation at high capacitance with low pulse frequency. Cathodes constructed from platinum coated stainless steel may exhibit a slight catalytic effect on methane conversion. Further, with increasing specific energy input, the energy efficiency for methane conversion has a minimum value, while the selectivity of acetylene has a maximum value. With improved reactor designs, pulsed corona discharge reactors may provide a viable alternative method for methane conversion at low temperatures.

\section{Acknowledgments}

This work was supported by CITGO, the Department of Energy (DE-FC26-03NT41963) and the University of Wyoming Research Office. The authors acknowledge that the intellectual 
force that initiated the project was that of Professor Pradeep Agarwal, who passed away in September 2002. The guidance provided by Mr. Steve Fischer of CITGO is deeply appreciated. In addition, the authors gratefully acknowledge experimental assistance provided by Mr. R. Borgialli. 


\section{Literature Cited}

(1) Holmen, A.; Olsvik, O.; Rokstad, O. A., Pyrolysis of natural gas: chemistry and process concepts. Fuel Processing Technology 1995, 42, 249-67.

(2) Fincke, J. R.; Anderson, R. P.; Hyde, T.; Detering, B. A.; Wright, R.; Bewley, R. L.; Haggard, D. C.; Swank, W. D., Plasma thermal conversion of methane to acetylene. Plasma Chemistry and Plasma Processing 2002, 22, (1), 105-136.

(3) Thanyachotpaiboon, K.; Chavadej, S.; Caldwell, T. A.; Lobban, L. L.; Mallinson, R. G., Conversion of methane to higher hydrocarbons in AC nonequilibrium plasmas. AIChE Journal 1998, 44, (10), 2252-2257.

(4) Yang, Y., Methane Conversion and Reforming by Nonthermal Plasma on Pins. Industrial \& Engineering Chemistry Research 2002, 41, (24), 5918-5926.

(5) Yang, Y., Direct Non-oxidative Methane Conversion by Non-thermal Plasma: Experimental Study. Plasma Chemistry and Plasma Processing 2003, 23, (2), 283-296.

(6) Onoe, K.; Fujie, A.; Yamaguchi, T.; Hatano, Y., Selective synthesis of acetylene from methane by microwave plasma reactions. Fuel 1997, 76, (3), 281-282.

(7) Heintze, M.; Magureanu, M.; Kettlitz, M., Mechanism of C2 hydrocarbon formation from methane in a pulsed microwave plasma. Journal of Applied Physics 2002, 92, (12), 7022-7031.

(8) Heintze, M.; Magureanu, M., Methane conversion into acetylene in a microwave plasma: Optimization of the operating parameters. Journal of Applied Physics 2002, 92, (5), 2276-2283.

(9) Huang, J.; Suib, S. L., Dimerization of methane through microwave plasmas. J. Phys. Chem. 1993, 97, (37), 9403-9407.

(10) Zhu, A.; Gong, W.; Zhang, X.; Zhang, B., Coupling of methane under pulse corona plasma (I) - in the absence of oxygen. Science in China, Series B: Chemistry 2000, 43, (2), 208214.

(11) Kado, S.; Sekine, Y.; Fujimoto, K., Direct synthesis of acetylene from methane by direct current pulse discharge. Chemical Communications 1999, (24), 2485-2486.

(12) Kado, S.; Urasaki, K.; Sekine, Y.; Fujimoto, K.; Nozaki, T.; Okazaki, K., Reaction mechanism of methane activation by using non-equilibrium pulsed discharge at room temperature. Fuel 2003, 82, (18), 2291-2297.

(13) Yao, S.; Nakayama, A.; Suzuki, E., Methane conversion using a high-frequency pulsed plasma: discharge features. AIChE Journal 2001, 47, (2), 419-426. 
(14) Yao, S.; Nakayama, A.; Suzuki, E., Acetylene and hydrogen from pulsed plasma conversion of methane. Catalysis Today 2001, 71, (1-2), 219-223.

(15) Yao, S.; Nakayama, A.; Suzuki, E., Methane conversion using a high-frequency pulsed plasma: important factors. AIChE Journal 2001, 47, (2), 413-418.

(16) Yao, S. L.; Suzuki, E.; Meng, N.; Nakayama, A., Influence of Rise Time of Pulse Voltage on the Pulsed Plasma Conversion of Methane. Energy \& Fuels 2001, 15, (5), 13001303.

(17) Yao, S. L.; Suzuki, E.; Meng, N.; Nakayama, A., A high-efficiency reactor for the pulsed plasma conversion of methane. Plasma Chemistry and Plasma Processing 2002, 22, (2), 225-237.

(18) Yao, S. L.; Suzuki, E.; Nakayama, A., The pyrolysis property of a pulsed plasma of methane. Plasma Chemistry and Plasma Processing 2001, 21, (4), 651-663.

(19) Uhm, H. S.; Lee, W. M., An Analytical Theory of Corona Discharge Plasmas. Phys. Plasmas 1997, 4, (9), 3117-3128.

(20) Mok, Y. S.; Ham, S. W.; Nam, I. S., Evaluation of Energy Utilization Efficiencies for $\mathrm{SO}_{2}$ and NO Removal by Pulsed Corona Discharge Process. Plasma Chemistry and Plasma Processing 1998, 18, (4), 535-550.

(21) Chung, J. W.; Cho, M. H.; Son, B. H.; Mok, Y. S.; Namkung, W., Study on reduction of energy consumption in pulsed corona discharge process for NOx removal. Plasma Chemistry and Plasma Processing 2000, 20, (4), 495-509.

(22) Zhao, G.-B.; Garikipati, S. V. B. J.; Hu, X.; Argyle, M. D.; Radosz, M., Effect of Reactor Configuration on Nitric Oxide Conversion in Nitrogen Plasma. AIChE J 2005, 51, (6), 1813-1821.

(23) Luo, J. S., Steven L.; Hayashi, Yuji; Matsumoto, Hiroshige., Emission Spectroscopic Studies of Plasma-Induced NO Decomposition and Water Splitting. Journal of Physical Chemistry A 1999, 103, (31), 6151-6161.

(24) Tanaka, S.; Uyama, H.; Matsumoto, O., Synergistic effects of catalysts and plasmas on the synthesis of ammonia and hydrazine. Plasma Chemistry and Plasma Processing 1994?, 14, (4), 491-504.

(25) Zhao, G.-B.; Hu, X.; Yeung, M. C.; Plumb, O. A.; Radosz, M., Nonthermal Plasma Reactions of Dilute Nitrogen Oxide Mixtures: $\mathrm{NO}_{\mathrm{x}}$ in Nitrogen. Industrial \& Engineering Chemistry Research 2004, 43, (10), 2315-2323.

(26) Hu, X.; Zhao, G.-B.; Legowski, S. F.; Radosz, M., Moisture Effect on NOx Conversion in a Nonthermal Plasma Reactor. Environmental Engineering Science 2005, 22, (6), 854-869. 
(27) Didden, C.; Duisings, J., On-line measurement of a liquid reactor feed with a mass spectrometer. Process Control and Quality 1992, 3, (1-4), 263-271.

(28) Zhao, G.-B.; Garikipati, S. V. B. J.; Hu, X.; Argyle, M. D.; Radosz, M., The Effect of Gas Pressure on NO Conversion Energy Efficiency in Nonthermal Nitrogen Plasma. Chem. Eng. Sci. 2005, 60, (7), 1927-1937.

(29) Kirikov, A. V.; Ryzhov, V. V.; Suslov, A. I., Kinetics of free radicals in the plasma of a spark discharge in methane. Technical Physics Letters 1999, 25, (10), 794-795.

(30) Denisov, G. V.; Kuznetsov, D. L.; Novoselov, Y. N.; Tkachenko, R. M., Influence of the parameters of a pulsed electron beam on the removal of nitrogen oxides from flue gases. Technical Physics Letters 1998, 24, (8), 601-602.

(31) Baulch, D. L.; Cobos, C. J.; Cox, R. A.; Esser, C.; Frank, P.; Just, T.; Kerr, J. A.; Pilling, M. J.; Troe, J.; al., e., Evaluated kinetic data for combustion modeling. Journal of Physical and Chemical Reference Data 1992, 21, (3), 411-734.

(32) Zhao, G.-B.; Hu, X.; Plumb, O. A.; Radosz, M., Energy Consumption and Optimal Reactor Configuration for Nonthermal Plasma Conversion of $\mathrm{N}_{2} \mathrm{O}$ in Nitrogen and $\mathrm{N}_{2} \mathrm{O}$ in Argon. Energy \& Fuels 2004, 18, (5), 1522-1530.

(33) Zhao, G.-B.; Hu, X.; Argyle, M. D.; Radosz, M., Effect of $\mathrm{CO}_{2}$ on Nonthermal-Plasma Reactions of Nitrogen Oxides in $\mathrm{N}_{2}$. Part II: Percent-level Concentrations. Ind. Eng. Chem. Res. 2005, 44, (11), 3935-3946.

(34) Zhao, G.-B.; Hu, X.; Argyle, M. D.; Radosz, M., Effect of $\mathrm{CO}_{2}$ on Nonthermal-Plasma Reactions of Nitrogen Oxides in $\mathrm{N}_{2}$. Part I: ppm-level Concentrations. Ind. Eng. Chem. Res. 2005, 44, (11), 3925-3934.

(35) Zhao, G.-B.; Hu, X.; Argyle, M. D.; Radosz, M., N Atom Radicals and $\mathrm{N}_{2}\left(\mathrm{~A}^{3} \Sigma_{\mathrm{u}}{ }^{+}\right)$Found to be Responsible for Nitrogen Oxides Conversion in Non-thermal Nitrogen Plasma. Ind. Eng. Chem. Res. 2004, 43, (17), 5077-5088.

(36) Zhao, G.-B.; Garikipati, S. V. B. J.; Hu, X.; Argyle, M. D.; Radosz, M., Effect of Oxygen on Nonthermal-Plasma Reactions of Nitrogen Oxides in Ntrogen. AIChE J 2005, 51, (6), 1800-1812.

(37) Zhao, G.-B.; Argyle, M. D.; Radosz, M., Effect of CO on Conversion of $\mathrm{NO}$ and $\mathrm{N}_{2} \mathrm{O}$ in Nonthermal Argon Plasma. Journal of Applied Physics 2006, 99, (11), 113302/1-113302/14.

(38) Shin, D. N.; Park, C. W.; Hahn, J. W., Detection of $\mathrm{OH}\left(\mathrm{A}^{2} \Sigma^{+}\right)$and $\mathrm{O}\left({ }^{1} \mathrm{D}\right)$ emission spectrum generated in a pulsed corona plasma. Bulletin of the Korean Chemical Society 2000, 21, (2), 228-232. 
(39) Eswaramoorthy, M.; Niwa, S.; Toba, M.; Shimada, H.; Raj, A.; Mizukami, F., The conversion of methane with silica-supported platinum catalysts: the effect of catalyst preparation method and platinum particle size. Catalysis Letters 2001?, 71, (1-2), 55-62.

(40) Souza, M. M. V. M.; Schmal, M., Methane Conversion to Synthesis Gas by partial Oxidation and $\mathrm{CO}_{2}$ Reforming over Supported Platinum Catalysts. Catalysis Letters 2003?, 91, (1-2), 11-17.

(41) Waku, T.; Biscardi, J. A.; Iglesia, E., Catalytic dehydrogenation of alkanes on Pt/Na[Fe]ZSM5 and staged $\mathrm{O}_{2}$ introduction for selective $\mathrm{H}_{2}$ removal. Journal of Catalysis 2004, 222, (2), 481-492.

(42) Eichwald, O.; Yousfi, M.; Hennad, A.; Benabdessadok, M. D., Coupling of Chemical Kinetics, Gas Dynamics, and Charged Particle Kinetics Models for the Analysis of NO Reduction from Flue Gases. J. Appl. Phys. 1997, 82, (10), 4781-4794.

(43) Blitz, M. A.; Beasley, M. S.; Pilling, M. J.; Robertson, S. H., Formation of the propargyl radical in the reaction of ${ }^{1} \mathrm{CH}_{2}$ and $\mathrm{C}_{2} \mathrm{H}_{2}$ : experiment and modeling. Physical Chemistry Chemical Physics 2000, 2, (4), 805-812. 


\section{Table Captions}

Table1. Experimental matrix

Table 2. Comparison of plasma processes for methane conversion 


\section{Figure Captions}

Figure 1. Experimental setup

Figure 2. Reactor electrical circuit diagram

Figure 3. Reactor outlet gas concentrations as a function of power input at a flowrate of $2.47 \times$ $10^{-5} \mathrm{~m}^{3} \cdot \mathrm{s}^{-1}$ and pulse-forming capacitance of $1920 \mathrm{pF}$. (a) SS tube, (b) Pt/SS tube, (c) Nb tube $\left(\square: \mathrm{CH}_{4}, \diamond: \mathrm{C}_{2} \mathrm{H}_{2}, \triangle: \mathrm{C}_{2} \mathrm{H}_{4}, \nabla: \mathrm{C}_{2} \mathrm{H}_{6}, \triangleleft: \mathrm{H}_{2}\right)$

Figure 4. Temperature of external reactor tube wall of $0.16 \mathrm{~m}$ from the outlet as a function of specific energy (measured in a geometrically-similar hydrogen switch-based plasma reactor).

Figure 5. The H/C ratio of outlet gas as a function of power input at a flowrate of $2.47 \times 10^{-5}$ $\mathrm{m}^{3} \cdot \mathrm{s}^{-1}$ and pulse-forming capacitance of $1920 \mathrm{pF}$.

Figure 6. The effect of capacitance on methane conversion and product selectivity for Pt/SS tube at a flowrate of $2.47 \times 10^{-5} \mathrm{~m}^{3} \cdot \mathrm{s}^{-1}$.

(1920 PF, $\mathbf{\square}: \mathrm{CH}_{4}$ conversion, $\mathbf{O}$ : Energy efficiency, $\diamond: \mathrm{C}_{2} \mathrm{H}_{2}$ selectivity, $\boldsymbol{\Delta}: \mathrm{C}_{2} \mathrm{H}_{4}$ selectivity, $\boldsymbol{\nabla}: \mathrm{C}_{2} \mathrm{H}_{6}$ selectivity, $\star$ : Carbon selectivity

$1280 \mathrm{PF}, \square: \mathrm{CH}_{4}$ conversion, $\mathrm{O}$ : Energy efficiency, $\diamond: \mathrm{C}_{2} \mathrm{H}_{2}$ selectivity, $\triangle: \mathrm{C}_{2} \mathrm{H}_{4}$ selectivity, $\nabla: \mathrm{C}_{2} \mathrm{H}_{6}$ selectivity, $\boldsymbol{\sim}^{2}$ : Carbon selectivity)

Figure 7. The effect of cathode material on methane conversion and product selectivity for SS tube and Pt/SS tube at a flowrate of $2.47 \times 10^{-5} \mathrm{~m}^{3} \cdot \mathrm{s}^{-1}$ and pulse-forming capacitance of $1920 \mathrm{pF}$.

(SS tube, $\mathbf{a}: \mathrm{CH}_{4}$ conversion, $\boldsymbol{O}$ : Energy efficiency, $\diamond: \mathrm{C}_{2} \mathrm{H}_{2}$ selectivity, $\boldsymbol{\Delta}: \mathrm{C}_{2} \mathrm{H}_{4}$ selectivity, $\nabla$ : $\mathrm{C}_{2} \mathrm{H}_{6}$ selectivity, $\star$ : Carbon selectivity

Pt/SS tube, $\square$ : $\mathrm{CH}_{4}$ conversion, $\mathrm{O}$ : Energy efficiency, $\diamond: \mathrm{C}_{2} \mathrm{H}_{2}$ selectivity, $\triangle: \mathrm{C}_{2} \mathrm{H}_{4}$ selectivity, $\nabla: \mathrm{C}_{2} \mathrm{H}_{6}$ selectivity, is: Carbon selectivity)

Figure 8. The effect of gas flowrates on methane conversion and product selectivity for SS tube at a pulse-forming capacitance of 1920 pF. (a) $400 \mathrm{~Hz}, 154 \mathrm{~W}$ power input, (b) $800 \mathrm{~Hz}$, $307 \mathrm{~W}$ power input

( $\square$ : $\mathrm{CH}_{4}$ conversion, $\bigcirc$ : Energy efficiency, $\diamond: \mathrm{C}_{2} \mathrm{H}_{2}$ selectivity, $\triangle: \mathrm{C}_{2} \mathrm{H}_{4}$ selectivity, $\nabla$ : $\mathrm{C}_{2} \mathrm{H}_{6}$ selectivity, $\succsim$ : Carbon selectivity, $\triangleleft: \mathrm{H}_{2}$ selectivity)

Figure 9. The effect of specific energy input on (a) $\ln (1-\mathrm{X})$, (b) energy efficiency, (c) acetylene, ethane, ethane, and carbon selectivities, and (d) $\mathrm{H}_{2}$ selectivity for the SS cathode.

Figure 10. Plot of $\ln (1-\mathrm{x})$ vs specific energy input. (a) Pt/SS tube; (b) Nb tube 
Table1. Experimental matrix

\begin{tabular}{|c|c|c|c|c|}
\hline Cathode material & $\begin{array}{c}\text { Tube length } \\
(\mathrm{m})\end{array}$ & $\begin{array}{c}\text { Flowrate } \\
\left(\times 10^{-5} \mathrm{~m}^{3} \cdot \mathrm{s}^{-1}\right)\end{array}$ & $\begin{array}{c}\text { Capacitance } \\
(\mathrm{pF})\end{array}$ & $\begin{array}{c}\text { Charge voltage } \\
(\mathrm{kV})\end{array}$ \\
\hline $\mathrm{SS}$ & 0.914 & $\begin{array}{c}2.47,3.71,4.94, \\
7.41,9.88\end{array}$ & 1920 & 20 \\
\hline $\mathrm{Pt} / \mathrm{SS}$ & 0.914 & 2.47 & 1280,1920 & 20 \\
\hline $\mathrm{Nb}$ & 0.609 & 2.47 & 1920 & 20 \\
\hline
\end{tabular}


Table 2. Comparison of plasma processes for methane conversion

\begin{tabular}{|c|c|c|c|c|}
\hline Literature & Plasma mode & $\begin{array}{c}\mathrm{CH}_{4} \text { flowrate } \\
\left(\mathrm{mol} \cdot \mathrm{s}^{-1}\right)\end{array}$ & $\begin{array}{l}\text { Frequency } \\
(\mathrm{Hz})\end{array}$ & \begin{tabular}{|c|} 
Energy \\
efficiency $(\%)$
\end{tabular} \\
\hline${\text { Fincke } \text { et } a .^{2}}^{2}$ & thermal arc & 0.098 & {$[-]$} & 25.2 \\
\hline Fincke et al. $^{2}$ & $\begin{array}{c}\text { thermal arc } \\
\text { (Huels process) }\end{array}$ & 26.45 & [-] & 33.2 \\
\hline Yao et al. ${ }^{17}$ & $\begin{array}{l}\text { corona discharge } \\
\text { (PTP reactor) }\end{array}$ & $2.03 \times 10^{-4}$ & $9.92 \mathrm{k}$ & 51.38 \\
\hline Yao et al. ${ }^{15}$ & $\begin{array}{c}\text { corona discharge } \\
\text { (CAC reactor) }\end{array}$ & $1.02 \times 10^{-4}$ & $8.0 \mathrm{k}$ & 17.69 \\
\hline This work & $\begin{array}{c}\text { corona discharge } \\
\text { (CAC reactor) }\end{array}$ & $\begin{array}{c}1.60 \times 10^{-3} \sim \\
6.40 \times 10^{-3}\end{array}$ & $0.1 \sim 1 \mathrm{k}$ & $10-32$ \\
\hline Yang $^{5}$ & $\begin{array}{c}\text { Dielectric barrier } \\
\text { discharge }\end{array}$ & $4.74 \times 10^{-5}$ & $10 \sim 40 \mathrm{k}$ & $<1$ \\
\hline Huang and Suib ${ }^{9}$ & Microwave & $\begin{array}{c}2.07 \times 10^{-5} \sim \\
2.54 \times 10^{-4}\end{array}$ & $2.45 \mathrm{G}$ & $0.2-3.3$ \\
\hline
\end{tabular}




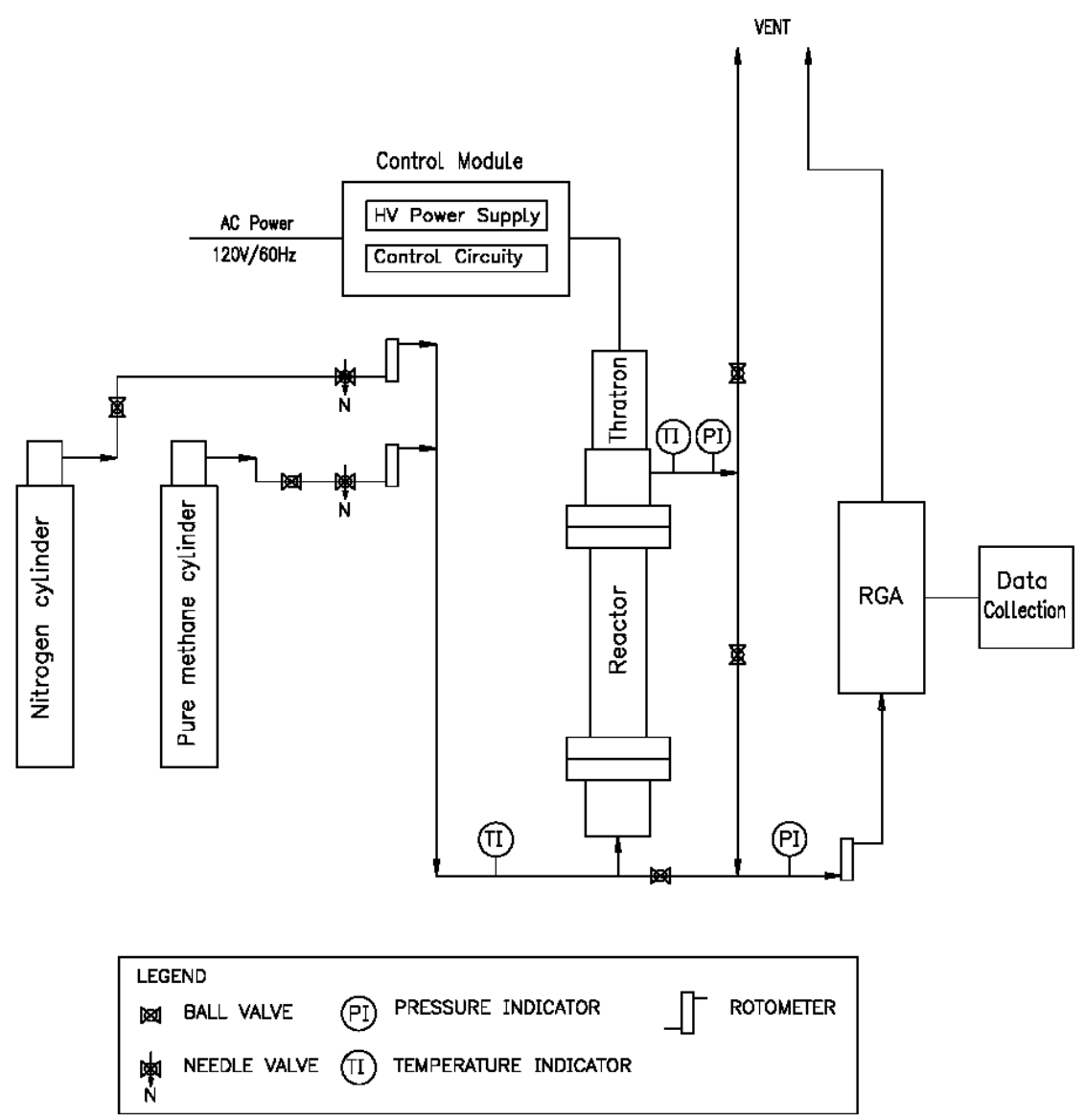

Figure 1. Experimental setup 


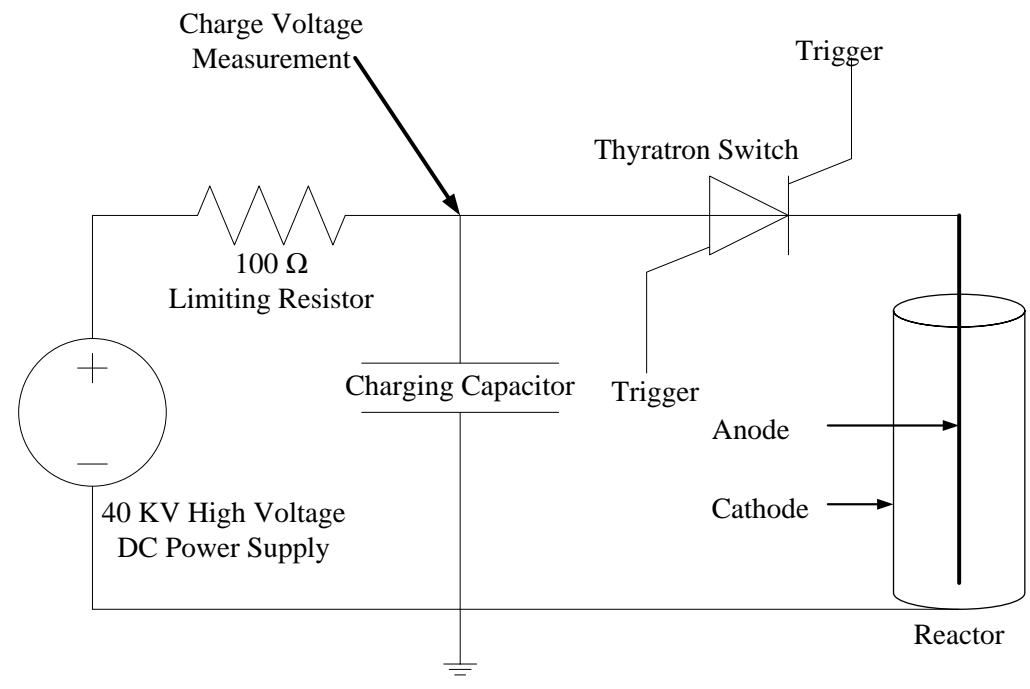

Figure 2. Reactor electrical circuit diagram. 

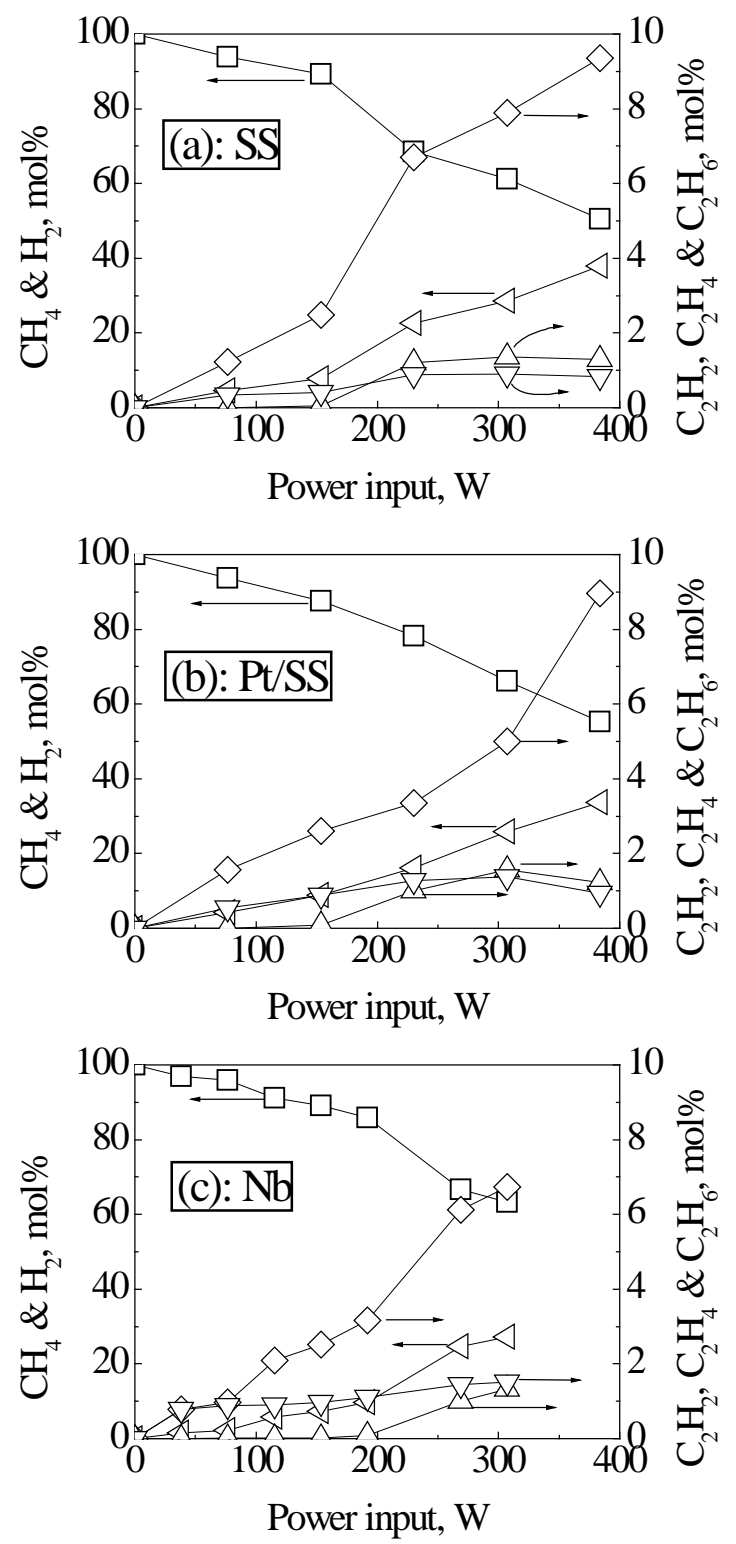

Figure 3. Reactor outlet gas concentrations as a function of power input at a flowrate of $2.47 \times$ $10^{-5} \mathrm{~m}^{3} \cdot \mathrm{s}^{-1}$ and pulse-forming capacitance of $1920 \mathrm{pF}$. (a) SS tube, (b) Pt/SS tube, (c) Nb tube ( $\square: \mathrm{CH}_{4}, \diamond: \mathrm{C}_{2} \mathrm{H}_{2}, \triangle: \mathrm{C}_{2} \mathrm{H}_{4}, \nabla: \mathrm{C}_{2} \mathrm{H}_{6}, \triangleleft: \mathrm{H}_{2}$ ) 


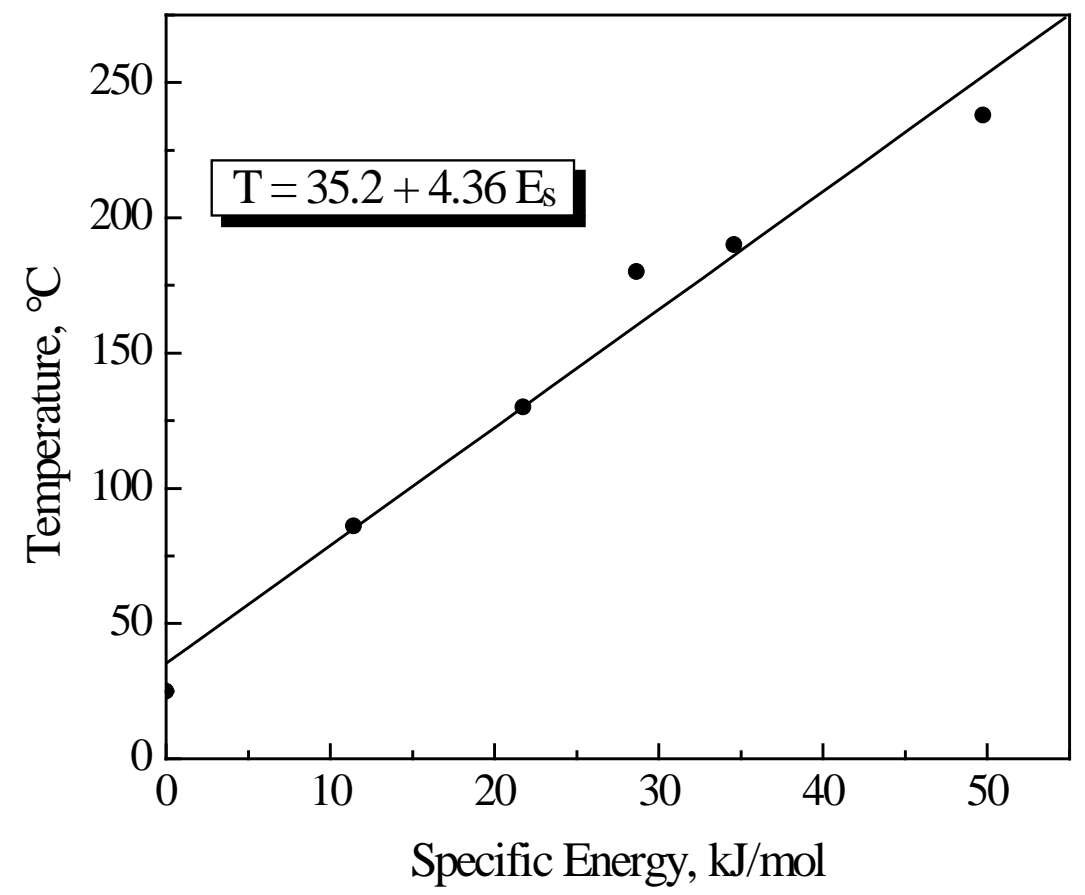

Figure 4. Temperature of external reactor tube wall of $0.16 \mathrm{~m}$ from the outlet as a function of specific energy (measured in a geometrically-similar hydrogen switch-based plasma reactor). 


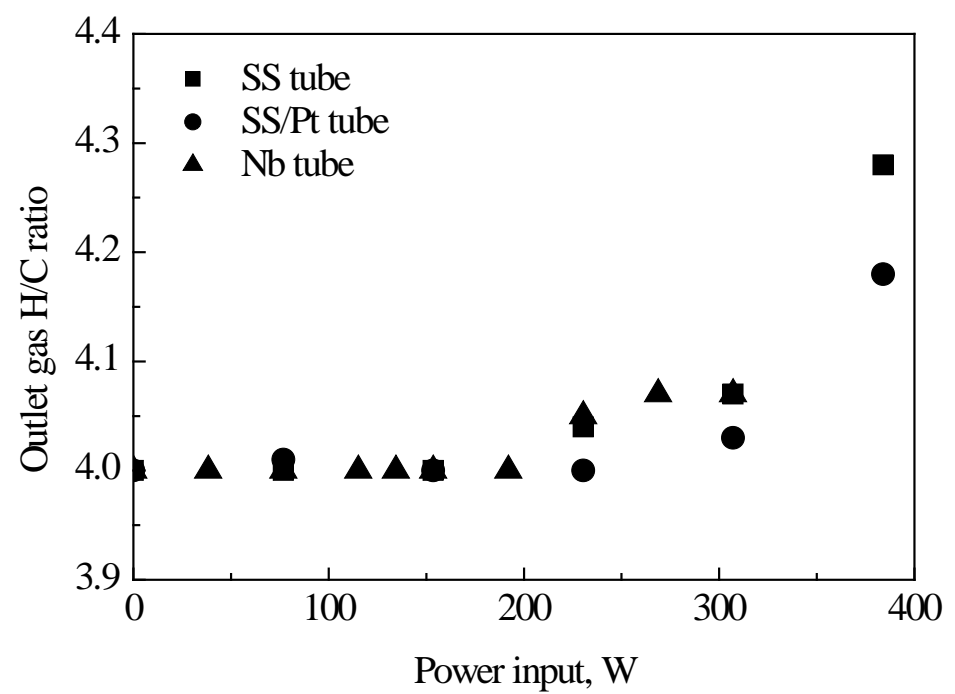

Figure 5. The H/C ratio of outlet gas as a function of power input at a flowrate of $2.47 \times 10^{-5}$ $\mathrm{m}^{3} \cdot \mathrm{s}^{-1}$ and pulse-forming capacitance of $1920 \mathrm{pF}$. 

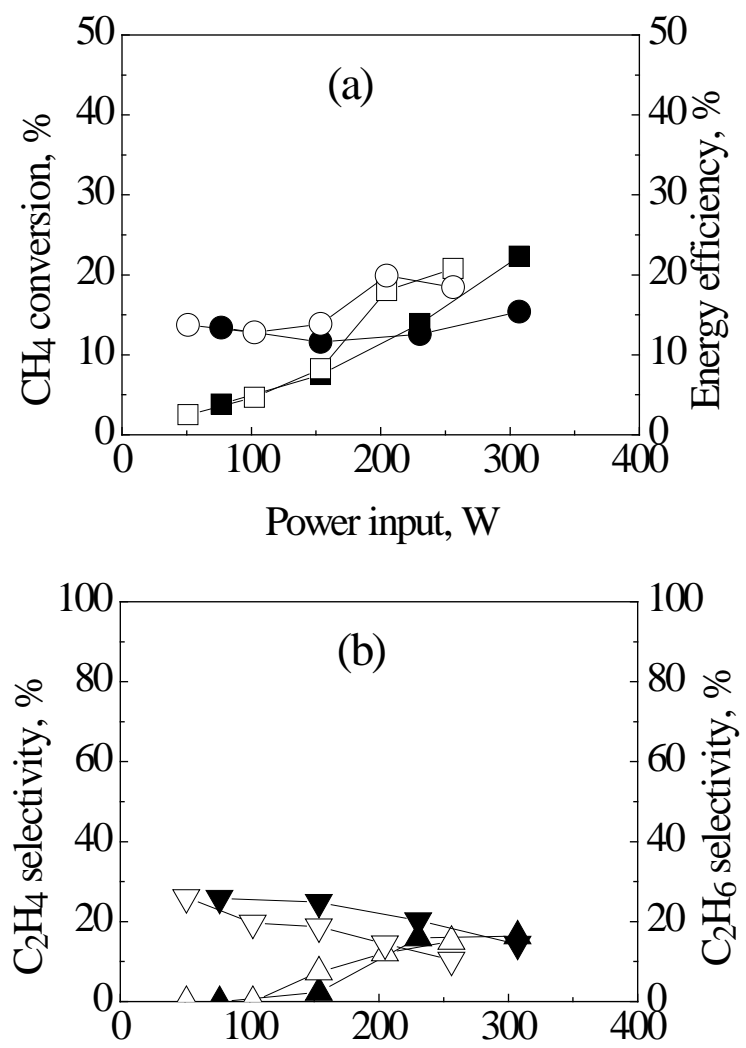

Power input, $\mathrm{W}$

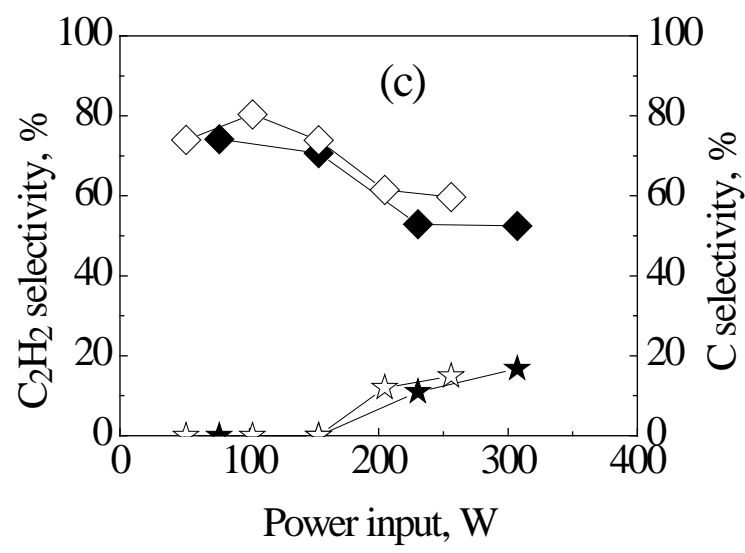

Figure 6. The effect of capacitance on methane conversion and product selectivity for Pt/SS tube at a flowrate of $2.47 \times 10^{-5} \mathrm{~m}^{3} \cdot \mathrm{s}^{-1}$.

(1920 PF, $\mathbf{\square}: \mathrm{CH}_{4}$ conversion, O: Energy efficiency, $\diamond: \mathrm{C}_{2} \mathrm{H}_{2}$ selectivity, $\boldsymbol{\Delta}: \mathrm{C}_{2} \mathrm{H}_{4}$ selectivity, $\nabla: \mathrm{C}_{2} \mathrm{H}_{6}$ selectivity, $\star$ : Carbon selectivity

$1280 \mathrm{PF}, \square$ : $\mathrm{CH}_{4}$ conversion, $\bigcirc$ : Energy efficiency, $\diamond: \mathrm{C}_{2} \mathrm{H}_{2}$ selectivity, $\triangle$ : $\mathrm{C}_{2} \mathrm{H}_{4}$ selectivity, $\nabla: \mathrm{C}_{2} \mathrm{H}_{6}$ selectivity, $\lrcorner$ : Carbon selectivity) 

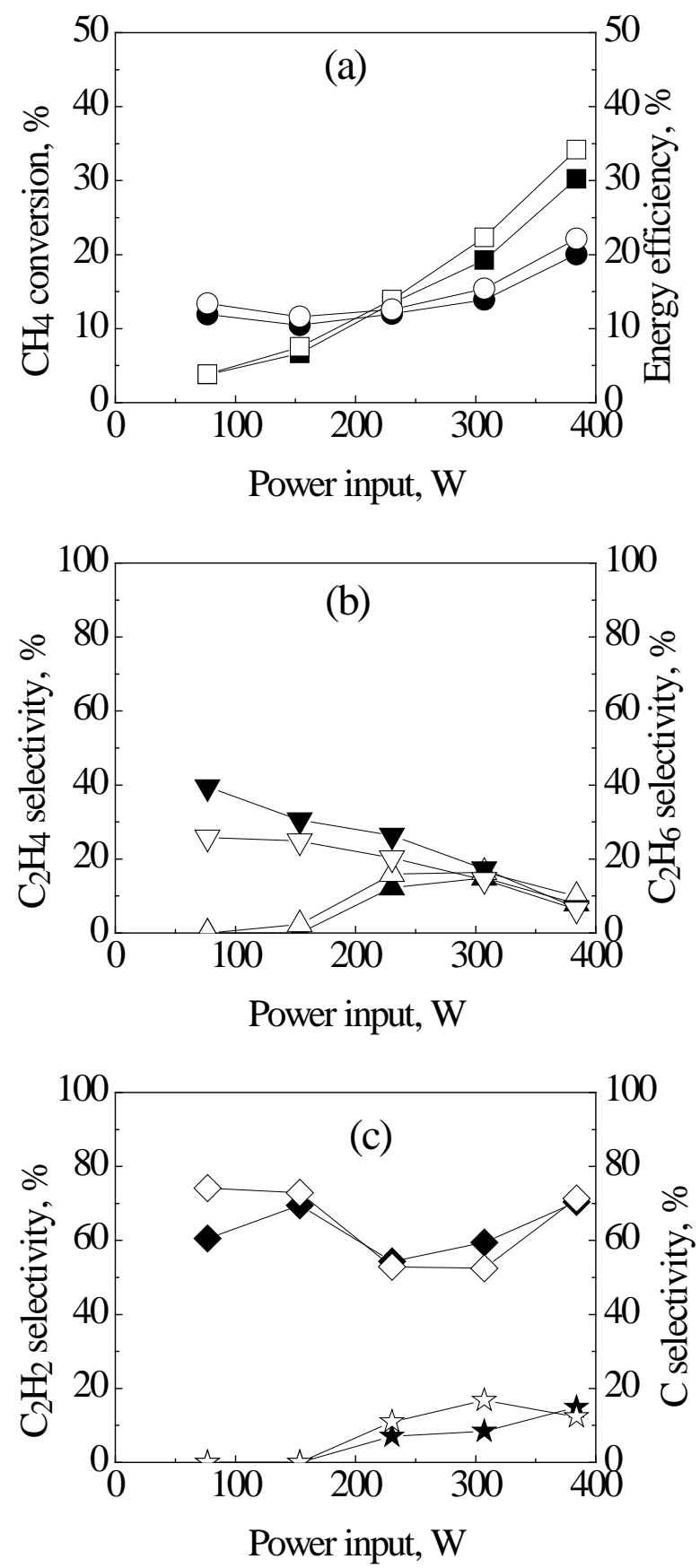

Figure 7. The effect of cathode material on methane conversion and product selectivity for SS tube and Pt/SS tube at a flowrate of $2.47 \times 10^{-5} \mathrm{~m}^{3} \cdot \mathrm{s}^{-1}$ and pulse-forming capacitance of $1920 \mathrm{pF}$. (SS tube, $\mathbf{\square}: \mathrm{CH}_{4}$ conversion, $\mathbf{0}$ : Energy efficiency, $\bullet: \mathrm{C}_{2} \mathrm{H}_{2}$ selectivity, $\boldsymbol{\Delta}: \mathrm{C}_{2} \mathrm{H}_{4}$ selectivity, $\nabla$ : $\mathrm{C}_{2} \mathrm{H}_{6}$ selectivity, $\star$ : Carbon selectivity

Pt/SS tube, $\square$ : $\mathrm{CH}_{4}$ conversion, $\bigcirc$ : Energy efficiency, $\diamond: \mathrm{C}_{2} \mathrm{H}_{2}$ selectivity, $\triangle$ : $\mathrm{C}_{2} \mathrm{H}_{4}$ selectivity, $\nabla: \mathrm{C}_{2} \mathrm{H}_{6}$ selectivity, $\vec{\imath}$ : Carbon selectivity) 

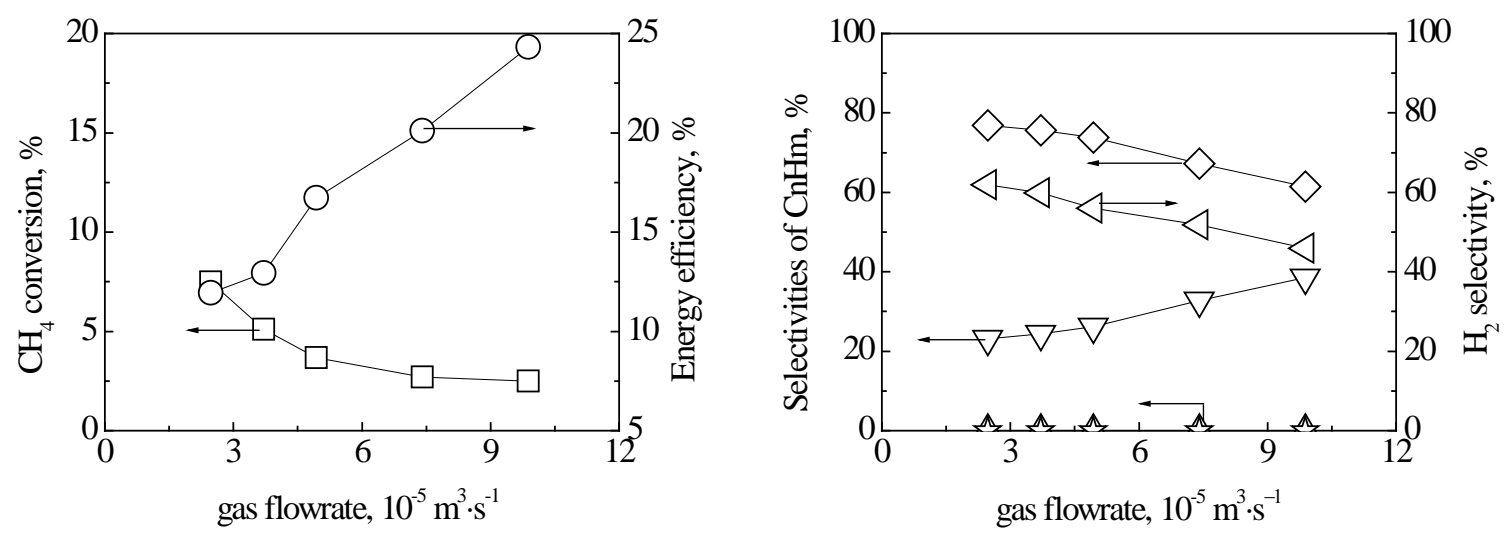

(a) $400 \mathrm{~Hz}, 154 \mathrm{~W}$ power input
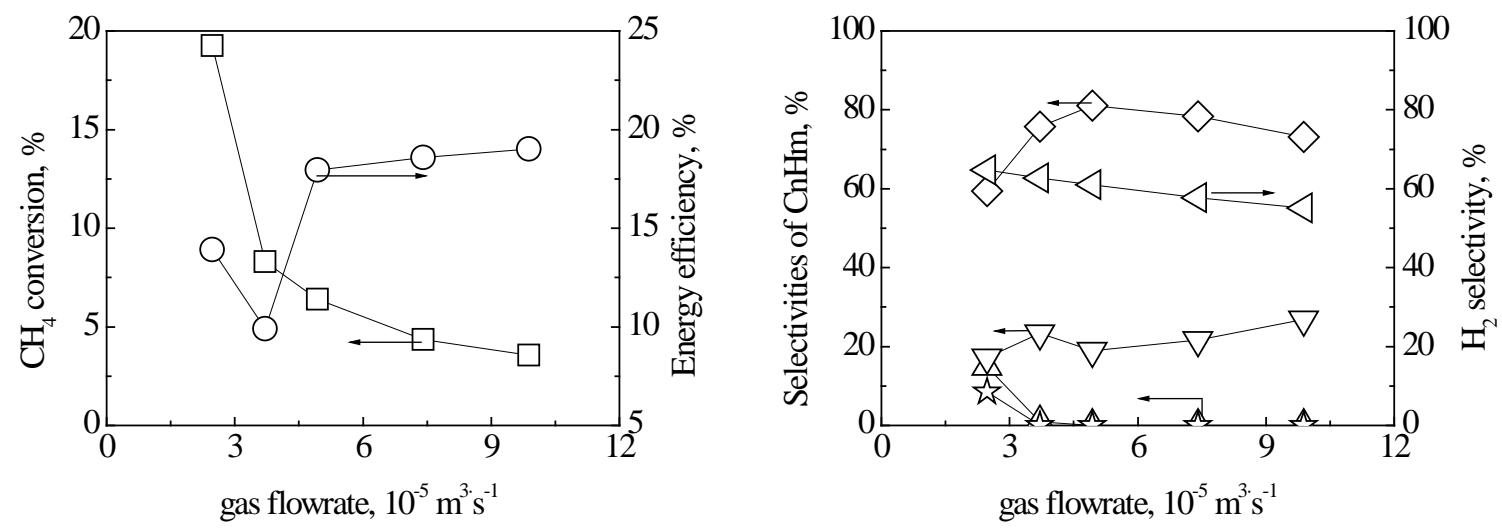

(b) $800 \mathrm{~Hz}, 307 \mathrm{~W}$ power input

Figure 8. The effect of gas flowrates on methane conversion and product selectivity for SS tube at a pulse-forming capacitance of $1920 \mathrm{pF}$.

( $\square$ : $\mathrm{CH}_{4}$ conversion, $\bigcirc$ : Energy efficiency, $\diamond: \mathrm{C}_{2} \mathrm{H}_{2}$ selectivity, $\triangle$ : $\mathrm{C}_{2} \mathrm{H}_{4}$ selectivity, $\nabla$ : $\mathrm{C}_{2} \mathrm{H}_{6}$ selectivity, $\downarrow$ : Carbon selectivity, $\triangleleft: \mathrm{H}_{2}$ selectivity) 

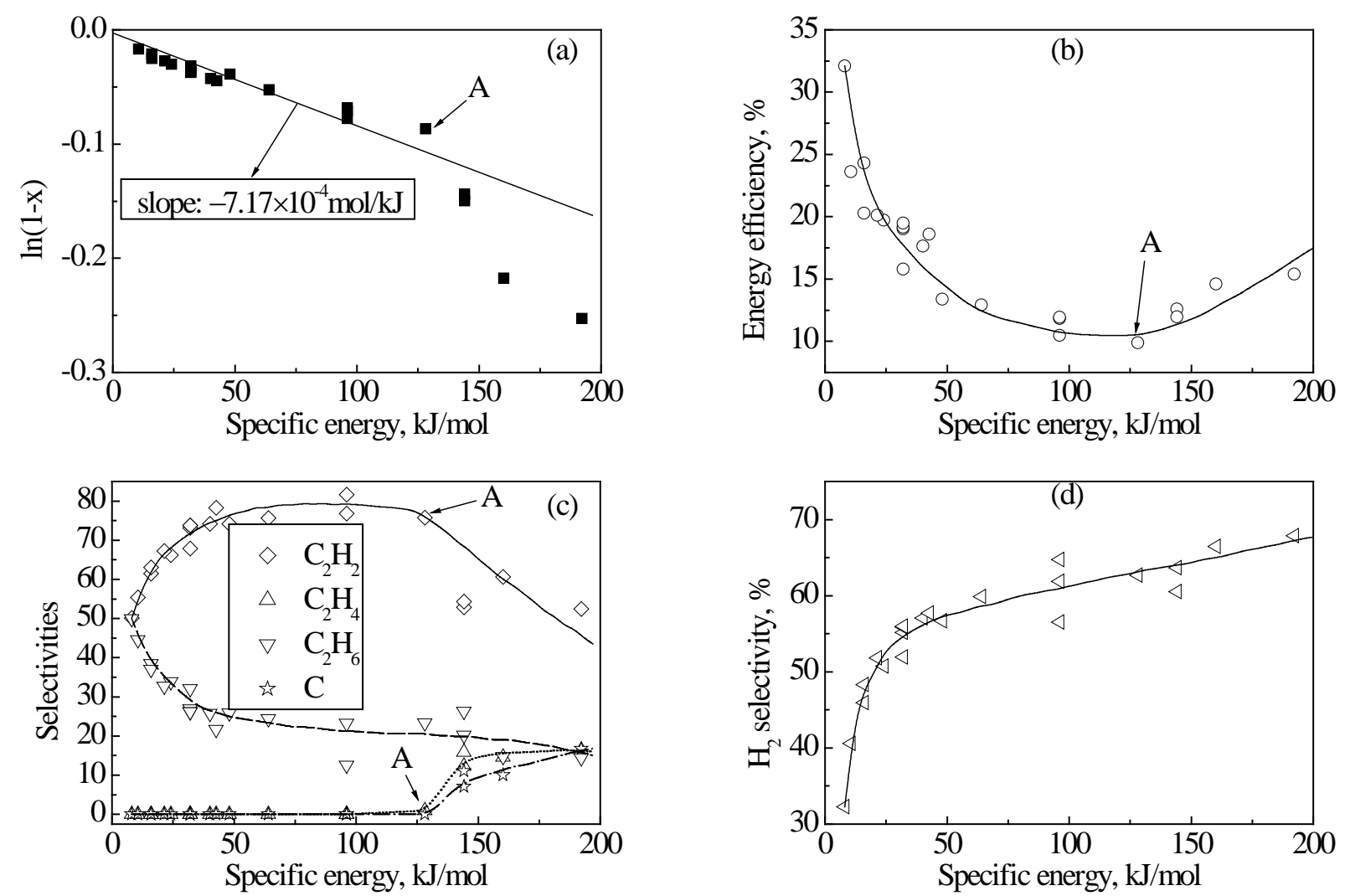

Figure 9. The effect of specific energy input on (a) $\ln (1-\mathrm{X})$, (b) energy efficiency, (c) acetylene, ethane, ethane, and carbon selectivities, and (d) $\mathrm{H}_{2}$ selectivity for the SS cathode. 

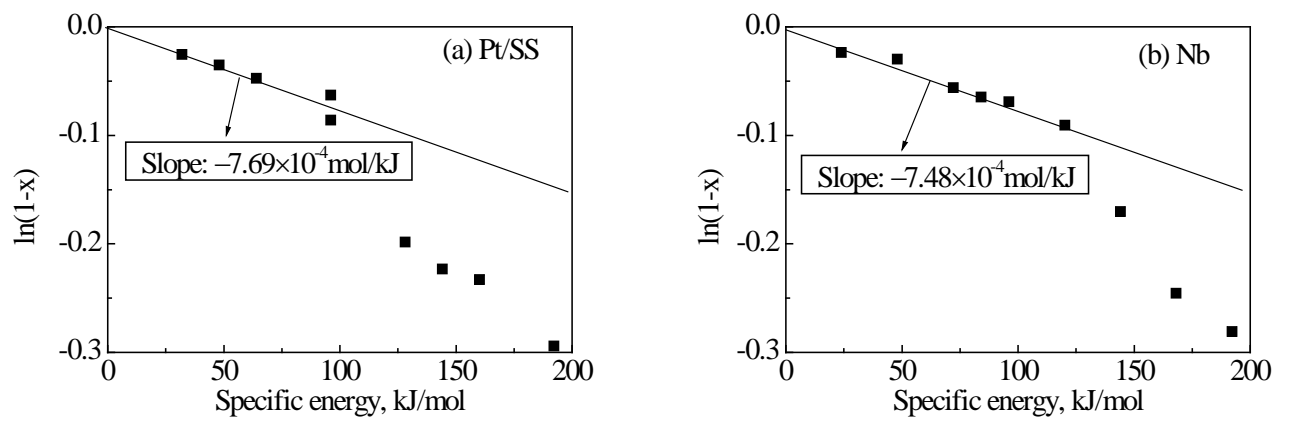

Figure 10. Plot of $\ln (1-\mathrm{X})$ vs specific energy input. (a) Pt/SS tube; (b) Nb tube 